\title{
Review Article \\ Chromatographic Methods in the Separation of Long-Chain Mono- and Polyunsaturated Fatty Acids
}

\author{
Małgorzata Dołowy and Alina Pyka \\ Department of Analytical Chemistry, Faculty of Pharmacy, Medical University of Silesia in Katowice, 4 Jagielloniska, \\ 41-200 Sosnowiec, Poland \\ Correspondence should be addressed to Alina Pyka; apyka@sum.edu.pl
}

Received 15 July 2014; Accepted 7 October 2014

Academic Editor: Hasan Uslu

Copyright (C) 2015 M. Dołowy and A. Pyka. This is an open access article distributed under the Creative Commons Attribution License, which permits unrestricted use, distribution, and reproduction in any medium, provided the original work is properly cited.

\begin{abstract}
This review presents various chromatographic systems, TLC, HPLC, GC, and also SFC, developed for identification and accurate quantification of long-chain mono- and polyunsaturated fatty acids from different samples with emphasis on selected literature which was published during last decade. Almost all the aspects such as preseparation step of fatty acids (cis and trans), stationary phase, solvent system, and detection mode are discussed.
\end{abstract}

\section{Introduction}

Long-chain fatty acids (LC-FA) are organic compounds in which the hydrocarbon chain length may vary from 10 to 30 carbons. The hydrocarbon chain can be saturated or unsaturated (contains one or more double bonds). Based on the number of double bonds, unsaturated fatty acids are classified into the following groups $[1,2]$ :

(i) monounsaturated fatty acids (monoenoic acids, MUFA), containing one double bond, for example, oleic acid,

(ii) polyunsaturated fatty acids (polyenoic acids, PUFA), having two or more double bonds, for example, $\gamma$ linolenic acid,

(iii) eicosanoids, which are derived from polyenoic fatty acids, for example, prostaglandins.

Recent literature data indicate that both monounsaturated and polyunsaturated fatty acids are biological important compounds which play a significant role for the living organisms [3-17]. Human feeding studies during the last ten years demonstrate that PUFA as well as MUFA are the main components of cholesterol-lowering diet $[4,7,9]$. Moreover, there has been a much interest in the effect of MUFA and PUFA on immune and inflammatory system [13]. Among various monounsaturated fatty acids, the most popular is oleic acid (C18:ln-9). It is found in plants (e.g., olive oil), animals, and microorganisms. Olive oil consumption has benefit for colon and breast cancer prevention [8]. The current studies show that oleic acid plays important role in prevention of coronary disease (ability to reduce LDL-cholesterol) [7, 9]. Polyunsaturated fatty acids similar to monounsaturated fatty acids are widely distributed in nature [18]. There are three classes of unsaturated fatty acids common in human tissues [5]: the $\omega-3$ (n-3 PUFA), $\omega-6$ (n-6 PUFA), and $\omega-9$ (n-9 PUFA) fatty acids. To the group of discussed unsaturated fatty acids belongs also demospongic acid, a mixture of very longchain fatty acids, mainly $\mathrm{C}_{24}-\mathrm{C}_{30}$ with the atypical 5,9diunsaturation system. It exists in microorganisms, marine invertebrates, and terrestrial plants [19]. The main sources of omega-3 are fishes, some plants, and green algae [20]. Green oleaginous algae are the potential source of the following $\omega-3$ acids: eicosapentaenoic (EPA), docosahexaenoic (DHA), and also arachidonic acid (AA) from $\omega-6$ group [21-23]. Omega6 PUFA are present in high concentration in grains as well as in many seeds and meats. From this reason we can notice an increase in the human consumption of seafood during several last years. Oleaginous microorganisms, as alternative sources of PUFA to others such as animal oil products, have been widely studied. Marine fungoid protists (Thraustochytrids) like Schizochytrium have been found to be as 
a novel, excellent DHA and EPA $\omega-3$ fatty acids producers $[24,25]$. An excellent review paper performed by Nichols demonstrates that many microorganisms including marine bacteria have been considered the major de novo producer of n-3 PUFA [26]. Available literature data suggest that over the past several years extensive research has been made for the production of PUFA by fungi $[27,28]$. As it was reported by Arjuna among various microorganisms, an optimal source of omega- 6 polyunsaturated fatty acids specifically $\gamma$-linolenic acid (GLA) can be certain fungi [27].

It is well known that PUFA can affect many physiological processes including cardiovascular, neurological, and immune functions, as well as cancer. Consumption of oils rich in n-3 LC-PUFA during pregnancy reduces the risk for early premature birth [12]. Studies with nonhuman primates and human newborns indicate that DHA is essential for the normal functional development of the retina and brain, particularly in premature infants [13, 29]. A new paper prepared by Kaczmarski et al. demonstrated the significant role of linoleic acid and also $\alpha$-linolenic acid in some symptoms of atopic dermatitis [17]. Therefore, it could be noted that PUFA are important nutraceutical and pharmaceutical targets [22].

Until today there is a lack of knowledge about the function of LC-PUFA in mammalian tissues and cells in which they are found. However, it was stated that very longchain polyunsaturated fatty acids are known to accumulate in two types of major genetic peroxisomal diseases, Zellweger syndrome and X-linked adrenoleukodystrophy (X-ALD), characterized by neurodegenerative phenotypes [30, 31]. The study of Hama and coworkers showed existence of many LCPUFA types in specimens from Zellweger patients suggesting the possibility of a new biomarker for peroxisomal diseases [31]. Review paper performed by Agbaga and coworkers [32] summarized the current knowledge of VLC-PUFA to their functional role in the retina which are highly enriched in PUFA with special emphasis on the elongases responsible for their synthesis by ELOVL4 protein. Interest in LC-PUFA was rekindled in 1987 after LC-PUFA were initially detected in bovine retinas by Aveldano [33]. Effect of retinal LCPUFA on rod and cone photoreceptors was also described by Bennett et al. [34]. Another paper prepared by Butovich confirmed that, among different mammalian tissues, meibum is an exceptionally complex mixture of various fatty acids [35].

Because most of LC-PUFA including omega-3 and omega- 6 fatty acids cannot be synthesized in enough quantity by the human organism, they must be supplied in the diet. The problem of supplementation of LC-PUFA and the exploration of a new (alternative to oil fish) source of LC-PUFA (e.g., marine microalgae) is widely described for few years in many papers. For this reason, there is a need to find an effective and rapid method for identification and quantification of newly developed long-chain mono- and polyunsaturated fatty acids in plants and seafood. A set of various tools such as chromatographic methods is also needed to complete the full structural characteristic of PUFA in mammalian samples, for example, in human plasma, brain, retina, or meibum. This is important for the purpose of clinical diagnosis.
Hence, this review presents various chromatographic systems, TLC, HPLC, GC, and also SFC, suitable for preseparation and accurate quantification of long-chain monoand polyunsaturated fatty acids from different samples with emphasis on selected literature which was published during last decade.

\section{Thin-Layer Chromatography (TLC) of Long-Chain Mono- and Polyunsaturated Fatty Acids}

Saturated and unsaturated long-chain fatty acids (MUFA and PUFA) are basic structural elements of lipids. Therefore, chromatographic determination of fatty acids composition by TLC including LC-MUFA and LC-PUFA content is mandatory for lipids analysis in food, agricultural, and also in biological samples [36-39]. Moreover, the monoand polyunsaturated fatty acids can be chromatographically determined by TLC in lipids from aquatic organisms (e.g., marine and freshwater fishes, shell fishes, and marine algae) [40].

It is well known that thin-layer chromatography is a classical method of separation, identification, and quantification of fatty acids [41]. The literature survey from the last decade dedicated to lipids analysis indicates that, among different analytical methods, thin-layer chromatography (TLC) and its modern version high performance thin-layer chromatography (HPTLC) are still very important tool in lipids and also in fatty acids analysis. As it was reported by Fuchs et al. [41], there are many advantages which make TLC very competitive with HPLC (high performance liquid chromatography) in the fatty acids field such as simplicity of use, less expensive cost, small consumption of solvents in comparison with HPLC, availability of analysis of several samples in parallel, and possibility of easy visualization of unsaturated fatty acids after TLC fractionation by use of suitable dyes [41]. Sherma's report regarding TLC analysis in food and agriculture samples confirmed that quantitative HPTLC equipped with densitometer can produce results comparable to those obtained by the use of gas chromatography (GC) or high performance liquid chromatography (HPLC) [42].

Modern topic in TLC analysis of mono- and polyunsaturated fatty acids is the use of high performance thin-layer chromatography in combination with mass spectrometric detection, for example, HPTLC-MALDI-TOF/MS [43-48]. Research studies indicate that MS detection is a powerful tool for the identification of TLC spots in more detail in comparison with traditional staining methods [41].

Many types of stationary phases classified as normal (NP) and reversed (RP) are used for TLC analysis of fatty acids (MUFA and PUFA). The most popular NP layers are silica gel, alumina, cellulose, starch, polyamides, and kieselguhr [42]. Of all above-mentioned stationary phases, the best is silica gel, which can be additionally modified by impregnation with different agents. Reversed-phase TLC is usually performed on chemically bonded RP-18, RP-2, or RP-8 layers [42].

Numerous research papers by Nikolova-Damyanova and other authors showed that the main reason which explains 
why TLC plays a significant role in fatty acid analysis is availability of various commercial and home-made adsorbents including impregnated TLC plates [36, 41, 49-51]. Impregnation of TLC plates with a proper reagent can improve the resolution of different classes of organic compounds including fatty acids. Among different modifications of stationary phases used in TLC, impregnated silica gel is a very suitable adsorbent for MUFA and PUFA analysis [41].

\subsection{Separation of MUFA and PUFA with the Use of Impreg-} nated TLC Plates. One of the primarily used TLC impregnating procedure to separate fatty acids in complex lipid samples was silver ion TLC (Ag-TLC). Detailed information on Ag-TLC of saturated and unsaturated fatty acids was performed in several papers and books [36, 49-51]. Silver ion chromatography is based on the ability of $\mathrm{Ag}^{+}$to form weak reversible charge transfer complexes with $\pi$ electrons of the double bonds of unsaturated fatty acids $[36,52]$. The retention of long-chain unsaturated fatty acids depends on the strength of complexation with $\mathrm{Ag}$ (I), on the number of double bonds and their configuration, and also on the distance between double bonds. Literature data indicate that both home-made and precoated glass plates are used in Ag-TLC [51]. General procedures of preparation of the stationary phases for silver ion chromatographic techniques have been surveyed by Momchilova and Nikolova-Damyanova, in 2003 [53]. Among various available TLC adsorbents, silica gel is the main supporting material [53]. Impregnation of thin layer is performed by spraying or immersing the plate in solution of silver nitrate at concentration of $0.5-20 \%$ (in the case of immersion), while for the spraying procedure $10-40 \%$ solution of silver nitrate is recommended [51,53]. The mobile phase used in argentation TLC usually consists of two or three components, for example, hexane, petroleum ether, benzene, and toluene. Moreover, small amount of acetone, diethyl ether, ethanol, methanol, or acetic acid may be added to these mobile phases [40]. Of various visualizing agents of spots, those which are most popular for Ag-TLC of fatty acids are $50 \%$ ethanol solution of sulfuric acid, phosphomolybdic acid, and a mixture of copper-acetate-phosphoric acid. Another visualizing method is spraying the plates with fluorescent indicator by $2^{\prime}, 7^{\prime}$-dichlorofluorescein in ethanol and next viewing the spots under UV light [36]. General migration rules in Ag-TLC analysis of fatty acids were described by Nikolova-Damyanova and coworkers [53,54]. According to Nikolova-Damyanova suggestions the retention of fatty acids with more than one double bond depends on the distance between the bonds and the elution order is as follows: separated double bonds fatty acids > interrupted double bonds > conjugated double bonds; longer chain unsaturated fatty acids (LC-PUFA) are held less strongly than shorter chain fatty acids and fatty acids with trans double bonds are held less strongly than fatty acids with cis double bonds $[53,54]$.

One of the first Ag-TLC analyses of fatty acids was performed by Wilson and Sargent in 1992 to separate PUFA having physiological interest. PUFA's methyl esters were separated on silica gel 60 TLC plates impregnated with $\mathrm{AgNO}_{3}$. The plates were developed with toluene-acetonitrile $(97: 3, \mathrm{v} / \mathrm{v})$. Visualization of the spots was made by the use of $3 \%$ copper acetate- $8 \%$ orthophosphoric acid. It was stated that this technique is particularly useful for metabolic studies of the chain elongated PUFA [55]. In another work Wilson and Sargent showed that silver nitrate-impregnated TLC plates were helpful in separation of monounsaturated fatty acids (as methyl esters) from polyunsaturated and also from saturated fatty acids, respectively, in metabolic studies of fatty acids by human skin fibroblasts [56]. Next work by Lin et al. indicated that silica gel and hexane-chloroformdiethyl ether-acetic acid $(80: 10: 10: 1, \mathrm{v} / \mathrm{v} / \mathrm{v} / \mathrm{v})$ were good in analysis of docosahexaenoic acid (22:6 DHA) in the spermatozoa of monkeys [57]. Individual phospholipids from this sample were separated by another system such as chloroform-methanol-petroleum ether-acetic acid-boric acid $(40: 20: 30: 10: 1.8, \mathrm{v} / \mathrm{v} / \mathrm{v} / \mathrm{v} / \mathrm{v})$. Other literature data confirmed that argentate silica gel chromatography enabled obtaining the high purity eicosapentaenoic acid extracted from microalgae and fish oils [58]. The recent literature reviews which were focused on TLC chromatography show that, among different chromatographic materials, Ag-TCMTLC (silver-thiolate silica gel) is very stable (in comparison with highly light sensitive Ag-TLC plates) for TLC analysis of unsaturated organic compounds including MUFA and PUFA. Dillon et al. [59] confirmed that Ag-TCM-TLC system operates similar to Ag-TLC by separating fatty acids on the degree of unsaturation (number of double bonds). The results of this analysis are comparable to those obtained by Ag-TLC. Ag-TCM-TLC method was used to analyze some polyhydrocarbons and also methyl esters of unsaturated fatty acids containing from 0 to 6 double bonds in form of methyl esters. A mixture consisting of hexane-ethyl acetate $(9: 1, \mathrm{v} / \mathrm{v})$ was used as mobile phase. Under these conditions complete separation of fatty acids with $0-5$ double bonds was observed. Resolution of fatty acids consisting of 6 double bonds from others was not achieved in this case [59].

The results presented in this section show that various commercial silica gel plates were used in separation of unsaturated fatty acids, but some of them are not suitable for derivatization process by methylation of fatty acids on TLC plates and next their quantification by gas chromatography, because it causes the loss of separated fatty acids [60]. Methylation procedure of fatty acids after their previous fractionation on argentate silica gel was used in the analyses of unsaturated fatty acids from lipid-rich seeds. In this case a mixture of hexane-diethyl ether-acetic acid and 70:30:1 $(\mathrm{v} / \mathrm{v} / \mathrm{v})$ was used as a mobile phase. The plates were sprayed with $2^{\prime}, 7^{\prime}$-dichlorofluorescein ethanolic solution and next identified under UV lamp (at $365 \mathrm{~nm}$ ) [60]. The impact of Ag-silica gel on TLC analysis of methylated fatty acids, for example, c9,t11-CLA (isomer of linoleic acid) in human plasma as a prior step before GC quantification was showed by Shahin et al. [61]. Another paper prepared by Kramer et al. demonstrated that the best technique to analyze the CLA and trans 18:1 isomers in synthetic and animal products is the combination of gas chromatography with $\mathrm{Ag}$-TLC or with Ag-HPLC [62]. Moreover, usage of Ag-TLC in the separation of isomeric forms of EPA and DHA obtained after chemical isomerization of them (during fish oil deodorization) may be found in a paper by Fournier et al. [63]. 
A new application of Ag-TLC is bioanalysis. A simple and rapid TLC method for analysis of PUFA levels in human blood was developed by Bailey-Hall et al. [64].

It should be pointed out that, besides the modification of silica gel with $\mathrm{Ag}^{+}$ions, the following metal salts, $\mathrm{Cu}(\mathrm{I})$, $\mathrm{Cu}(\mathrm{II}), \mathrm{Co}(\mathrm{III})$, and $\mathrm{Zn}$ (II), can be used for impregnation of TLC plates [41, 65]. Another type of impregnating agent for TLC analysis of fatty acids (MUFA and PUFA) is boric acid. It was stated that the metabolites of arachidonic acid were satisfactorily separated on silica gel impregnated with boric acid as complexing agent and by mobile phase: hexane-diethyl ether $(60: 40, \mathrm{v} / \mathrm{v})[41,65]$. Next modification of stationary phase which has impact on resolution effect of fatty acids and their derivatives such as metabolites (e.g., phospholipids) is EDTA and mobile phase containing chloroform-methanolacetic acid water in volume composition of $75: 45: 3: 1$ [41, 66]. Another work showed that efficient separation of five different phospholipids could be achieved by impregnation of TLC plates with $0.4 \%$ ammonium sulfate. A mixture of chloroform-methanol-acetic acid-acetone-water in volume composition of $40: 25: 7: 4: 2$ was suitable for this procedure [67].

Besides the above-presented TLC system in normal phase (NP-TLC), unsaturated fatty acids and their metabolites could be separated on RP-TLC plates. One of the first reports which are focused on RP-TLC analysis of PUFA was made by Beneytout and coworkers in 1992 [68]. Beneytout et al. separated arachidonic acid and its metabolites on reversed-phase layer. The plates were silica gel coated with phenylmethylvinylchlorosilane. A mixture of heptanemethyl formate-diethyl ether-acetic acid (65:25:10:2, v/v/v/v) was applied as mobile phase [68].

2.2. 2D-TLC of MUFA and PUFA. Two dimensional TLC (2D-TLC) is one of the newly developed powerful tools to separate various lipids mixture and fatty acids coming from lipids. It is known that 2D-TLC improved the quality of separation, but it is much more time consuming in comparison with very popular 1D-TLC [41]. Literature review showed that 2D-TLC is rather a method of choice for separation of lipids from cell membrane polyphosphoinositides and also of lipid oxidation products in mixture. This analysis is usually performed on silica gel impregnated with magnesium acetate $(7.5 \%)$ and by solvent system chloroformmethanol-ammonia $(5: 25: 5, \mathrm{v} / \mathrm{v} / \mathrm{v})$ in the first direction and chloroform-acetone-methanol-acetic acid water $(6: 8: 2: 2.1$, $\mathrm{v} / \mathrm{v} / \mathrm{v} / \mathrm{v}$ ) in the second dimension [69].

2.3. Detection of Spots and Quantification Methods of MUFA and PUFA. Detection of fatty acids by TLC method is based on their visualization by binding to a dye. As is was reported in excellent review by Fuchs et al. [41] a lot of visualizing reagents suitable for detection of fatty acids are described in the literature. Among them, the most popular reagents are iodine vapors, $2^{\prime}, 7^{\prime}$-dichlorofluorescein, rhodamine $6 \mathrm{G}$, which produce coloured spots, and also primuline, which gives sensitivities in the nanomole range [41]. In case of PUFA intense darkening is achieved after their separation on $\mathrm{AgNO}_{3}$ impregnated TLC plates (as an effect of reduction of $\mathrm{Ag}^{+}$to colloid silver), but this method of detection required the presence of aromatic hydrocarbon as mobile phase component [70]. Other visualizing reagents are as the following: sulfuric acid, potassium dichromate in $40 \%$ sulfuric acid, or 3-6\% solution of cupric acetate in phosphoric acid. Moreover, detection of different fatty acids is possible by PMA (phosphomolybdic acid) and by sulfuryl chloride vapors [41]. Visualization of fatty acid spots is performed by spraying or dipping the plates in solution of respective visualizing agents. Next, the spots are observed under UV light or identified by densitometry. For more detailed characterization of fatty acids which have been separated by thin-layer chromatography, TLC combined with mass spectrometer (TLC-MS) may be used. In this method the spots are eluted from the chromatographic plates with respective solvents and next obtained fatty acids are analyzed by MS. Applying of TLC coupled with MS enables high resolution of identified peaks. Moreover, there is no need to extract sample from the plates prior to this analysis [41]. A novelty in thin-layer chromatographic instrumentation is a TLC in combination with MALDI MS spectrometer (TLC MALDI) [44, 71, 72]. This technique is rather fast and provides spectra that can be relatively simply analyzed and tolerates high sample contamination [41]. The detection limit of fatty acids determined by TLC MALDI might be less than 1 nanogram [41]. It was stated that TLC MALDI could be satisfactorily applied to very complex lipid mixture (e.g., extracts from stem cells) [47]. For example, by means of combined thin-layer chromatography and MALDI-TOF/MS analyses of the total lipid extract of the hyperthermophilic archaeon Pyrococcus furiosus were performed [45]. Next modern trend in analysis of lipid profile is the use of TLC method coupled with FID (flame ionization detector) [73]. Chromarod/ Iatroscan TLC-FID was successfully used in the analysis of lipid classes and their constituents of fatty acids extracted from seafood. As it was described in the paper by Sinanoglou et al. [73], Iatroscan is an instrument that combines TLC resolution with capacity of quantification by FID. Efficient TLC-FID separation can be achieved by addition of polar solvent system without changing the stationary phase. However, this apparatus allows analyzing in a short time (2$3 \mathrm{hr}$ ) in comparison with GC or HPLC about 30 samples [73].

\subsection{TLC Separation of cis and trans Isomers of MUFA and} $P U F A$. Since it was reported that the saturated fatty acids indicate correlation with cardiovascular diseases, unsaturated fatty acids have been recommended for replacement of saturated fatty acids in a diet. For this reason, an increase of interest in unsaturated fatty acids such as n-6 and n3 fatty acids is observed. It is known that the discussed unsaturated fatty acids form specific geometrical isomers. They can be trans or cis depending on the orientation of double bond. Of all polyunsaturated fatty acids the trans PUFA consisting of C18, C20, and C22 chain lengths are usually part of the human diet. Thus, it is very important to detect and quantify them in food products. One of the most popular method obtaining the mono-, di-, and triunsaturated fatty acids in form of geometrical isomers 
(cis and trans), respectively, is thermal or chemical process [63]. Synthesis of trans isomers is usually made by food manufacturing (refining, hydrogenation). For instance, trans isomers are formed during deodorization (crucial step of refining) of vegetable or fish oils. As it was reported by Fournier et al. [63], the methodologies regarding accurate separation and quantification of trans isomers of mono-, di-, and triunsaturated fatty acids by chromatographic methods were developed in the last decade. Ag-TLC is one of the most powerful chromatographic techniques widely applied to separate cis and trans isomers of LC-PUFA because it is characterized by simplicity, low cost, and efficiency. Geometrical isomers are separated according to their number of double bonds. The efficacy of Ag-TLC for separation of EPA and DHA isomers was confirmed by Fournier et al., in 2006 [63]. For this purpose TLC plates precoated with silica gel and impregnated by $\mathrm{AgNO}_{3}$ were used. A mixture of toluene-methanol in the volume composition $85: 15$ was applied as a mobile for resolution of EPA mono-, di-, tri-, tetra-, penta-trans and DHA hexa-trans isomers [63]. In another work, in order to determine the profile of cis and trans isomers of CLA in liver by the TLC method, a mixture of trichloromethane-n-hexane-glacial ethanoic acid $65: 35: 1$ $(\mathrm{v} / \mathrm{v} / \mathrm{v})$ and also silica gel plates were applied. Rhodamine solution was used as a visualizing agent. In further steps, after methylation of separated fatty acids they were quantified by GC method [74].

Next paper indicated that preparative silver nitrate thinlayer chromatography was successfully applied to analyze the cis,cis-octadecadienoic acid $(18: 2)$ in commercial samples of bovine butter fat. The detected by Ag-TLC cis,cis-5,918:2 isomer was found for the first time in butter fat [54]. In another food study, ninety-three commercial samples of Bulgarian butter fats manufactured evenly through the year were subjected to quantitative silver nitrate-TLC of fatty acids components (as isopropyl esters), with particular attention to trans monoenoic fatty acid content [75]. All performed results indicate that argentation TLC should be an effective analytical technique in fractionation and identification of geometric isomers of unsaturated fatty acids such as PUFA.

Table 1 shows the most efficient TLC systems used for separation and fractionation of fatty acids from various matrices.

\section{High Performance Liquid Chromatography (HPLC)}

There are few excellent original papers and reviews until today which are focused on usage of liquid column chromatography for the analysis of fatty acids (saturated and unsaturated) and also their related substances in biological, food, and drugs samples [18, 93-96]. In these papers principles of HPLC including the sample preparation, mobile phases, stationary phases, and detection methods were widely performed. Among the earlier review papers, only three of them survey knowledge of long-chain fatty acids. One of them prepared by Rao et al. [94] showed the LC-PUFA analysis with use of HPLC but since 1974 until 1995. Next paper supported by Rezanka and Votruba [96] demonstrated the use of chromatography including HPLC for analysis of very long-chain fatty acids from 1982 to 2001 . The third review prepared by Kolanowski and coworkers [97] described the important instrumental methods such as HPLC and also GC for analysis of omega-3-long-chain polyunsaturated fatty acids but in food only. Lack of the overview about the new achievements in HPLC analysis of mono- and polyunsaturated fatty acids with an emphasis on the analysis of long-chain polyunsaturated fatty acids such as omega-3 and omega- 6 causes that there is a necessity to perform a complete literature survey from 2002 to 2013 (last decade) with emphasis on application of HPLC for the analysis of all biological important LC-MUFA and LC-PUFA at the analytical levels in various matrices. This paper highlights the modern achievements of the HPLC including the principles of MUFA and PUFA analysis in different matrices: separation modes and the new detection systems which enable quantification of LC-PUFA at nanogram level. The current knowledge of HPLC analysis of mono- and polyunsaturated fatty acid was described on the basis of the works which were published during the past decade (2002-2013).

The use of HPLC for the separation and quantification of fatty acids increased since 1950, when it was applied for first time by Haward and Martin for analysis of some fatty acids [98]. From this time until today a very quick progress in HPLC analysis of all fatty acids including LC-MUFA and LC-PUFA is observed. It is known that, based on nature of stationary phase (solid or liquid), the high performance liquid chromatography is divided into [18] liquid-liquid chromatography (LLC), adsorption chromatography (LSC), and reversed-phase chromatography (RP), which is a combination of LSC and LLC.

Among above-mentioned high performance liquid chromatographic techniques RP-HPLC plays a key role in LCPUFA analysis [94]. This technique allows separating those fatty acids which cannot be separated by normal phase HPLC. As it was early reported by Rao et al. [94] the retention of fatty acids in RP-HPLC depends on the polarity of the stationary phase, mobile phase, and chemical structure of examined fatty acids. In general, the retention time is proportional to the chain length and the number of double bonds present in examined fatty acids. Additionally, the influence of geometric isomerization of fatty acids plays a very important role in reversed-phase HPLC analysis. It was reported that the cis isomers of the fatty acids are generally eluted before trans isomers. Similar effect is observed in case of the differences in number of carbons in studied fatty acids. Those with small amount of carbons (short chain) are eluted first in comparison with long-chain fatty acids [94]. The current literature indicates that the reversed-phase HPLC is one of the popular methods used in the field of fatty acids analysis of MUFA and PUFA because its simplicity, reproducibility, and credibility. The results obtained by HPLC are usually comparable with those determined using GC method. Moreover, the time of analysis is comparable to GC technique [94]. However, development of new detector mode such as flame ionization detector (FID) or electrochemical detector (ED) enhances the applicability of HPLC for MUFA and PUFA analysis [93]. 


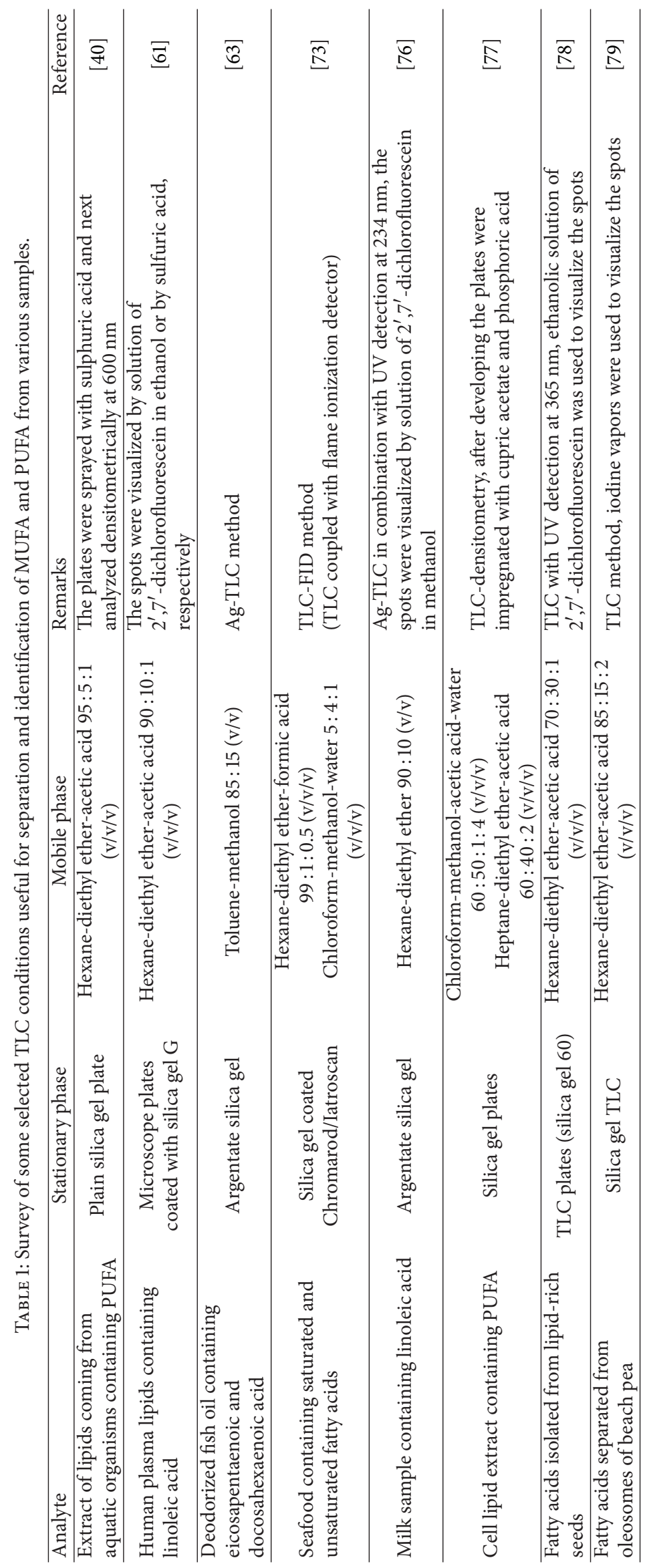


3.1. Derivatization Methods of Fatty Acids for HPLC Analysis. The most important problem in HPLC study of LC-MUFA and also LC-PUFA is a need to detect them at lower concentration levels such as nanograms or picograms. Derivatization of fatty acids can improve the importance for HPLC analysis parameters such as sensitivity, precision, selectivity, and also a limit of detection and quantification [18, 95]. Different derivatization methods used for quantitative and qualitative determination of fatty acids were widely described in review paper by Rosenfeld in 2002 [99]. Generally, the kind of derivatizing agent depends on the type of detector applied in PUFA analysis including UV absorption, fluorescence, light scattering, and refractive index detectors [94].

UV-VIS detector is the most popular detection system applied in liquid chromatography because it is sensitive and specific. In 1983 Aveldano and coworkers [100] have applied reversed-phase high pressure liquid chromatography with UV detection on octadecylsilyl column to separate a mixture of underivatized unsaturated and saturated fatty acids and their methyl esters coming from mammalian tissues.

Generally in order to facilitate the detection by UVVIS absorption the following derivatizing reagents for fatty acids are used [93]: phenacyl bromide (PB), p-bromophenacyl bromide (BPB), p-chlorophenacyl bromide (CPB), p-nitrophenacyl bromide which are used in analysis of fatty acids in oils, standards, and blood in the range from ng to pmol [97]. Naphthyl esters (obtained by 2-naphthyl bromide, p-nitrophenacyl, and p-dichlorophenacyl allow for the detection of picograms fatty acids in standard mixture. 2-Nitrophenylhydrazine (NPH) and 2-bromoacetophenone (or $\alpha$,p-dibromoacetophenone, BAP) convert the fatty acids into specific derivatives which can be detected in biological samples (serum) with detection limits in fmoles. PNB (p-nitrobenzyl) and p-methylthiobenzyl chloride (MTBC) derivatives of fatty acids with detection limits in pmoles are important in coconut oil analysis. Ideal derivatizing reagent for chiral separation of fatty acids is 3,5-dinitrophenyl isocyanate (DNPI) [96].

Next very popular detection system applied in HPLC is fluorescence detector which has higher sensitivity in comparison with UV-VIS detector. For this reason it could quantify the fatty acids composition at picomole and femtomole level. Several fluorescent reagents are used for the derivatization of fatty acids such as 9-diazomethylanthracene (9-DMA) and 9-anthryldiazomethane (ADAM). Anthryl methyl esters of fatty acids can be easily detected in human plasma and serum in picomoles. Other more sensitive derivatives than ADAM are the esters of pyrenyldiazomethane (PDAM). Coumarins and 9-aminophenanthrene (9-AP) are important in detection of fatty acids in environmental and in biological samples in the range from pmoles to fmoles. Other derivatives like dansyl piperazines and acetamides of fatty acids can be detected in serum below $100 \mathrm{fmol}$ range [93, $94,97]$. Recent study performed by Wang and coworkers in 2013 indicates that using a new fluorescent labeling reagent named 1,3,5,7-tetramethyl-8-butyrethylendiamine-difluoroboradiaza-s-indacene (TMBB-EDAN) a sensitive and rapid HPLC technique for the determination of fatty acids in biosamples (e.g., human serum) was developed. With the proposed procedure the limit of detection of fatty acid derivatives was in the $0.2-0.4 \mathrm{nM}$ range [101].

Another type of fatty acids detection is chemiluminescence. This method is based on the prelabeling of the $-\mathrm{COOH}$ groups with a proper chemiluminogenic reagent. In practice luminal and its related compound isoluminal have been widely utilized as chemiluminescence derivatization reagents for fatty acids because of their chemiluminescent properties. Described detection system is efficient for the sensitive detection of fatty acids in human serum and plasma in picomoles [93].

In order to detect the substances with oxidizing or reducing properties including fatty acids an electrochemical detector (ED) may be used. This detection mode enables measure of fatty acids in complex biological samples containing different components at nanogram levels. To obtain the higher sensitivity the following derivatizing reagents for ED can be applied: p-aminophenol; 2,4-dimethoxyaniline; 2-bromo-2' nitroacetophenone; ferrocene derivatives; 2,4 -dinitrophenylhydrazine and 3,5-dinitrobenzoyl chloride. Clinical application of HPLC-ED is showed in the paper by Kotani et al. [80]. In this work determination of plasma fatty acids including PUFA such as arachidonic acid and also linoleic by high performance liquid chromatography coupled with electrochemical detector (HPLC-ED) was performed [80]. This procedure may be found suitable for monitoring plasma fatty acids in diabetic patients.

Among different types of detectors used in HPLC analysis of fatty acids, very useful is that detector which requires none of the preliminary derivatization procedures of studied compounds like, for example, evaporative light-scattering detector (ELSD) or mass spectrometer (MS) [93]. As it was described in paper by Lima and Abdalla [93] evaporative light-scattering detector is sensitive to mass of vaporized analyte and its operation system is not limited by the absorption characteristics of the individual components and nature of the eluent. Thus, ELSD may be used to solve the problem of separation of fatty acids which have weak absorbance groups [93].

3.2. Mass Spectrometry Detection of Fatty Acids. Application of HPLC-MS in analysis of fatty acids is known only from the last decade. Mass spectrometer is extensively used in analysis of fatty acids especially in case of biological samples. One of the main advantages of HPLC-MS method is possibility to analyze nonvolatile compounds including fatty acids [93]. Numerous ionization and detection modes can be applied for fatty acids analysis such as electrospray ionization (ESI), atmospheric pressure chemical ionization (APCI), and also time of flight (TOF). A new possibility in HPLC-mass spectrometry is tandem MS (HPLC-MS-MS) or combination of electrospray ionization with tandem mass spectrometer such as HPLC-ESI-MS-MS technique. The major advantage of LCESI is the great separation of fatty acids in complex matrices like blood plasma. HPLC-MS-MS is a powerful tool in determination of double bond position or branched points in the chain of unsaturated fatty acids [93]. Next HPLC method developed for detection of long-chain fatty acids is HPLC-MS method combined with APCI, which was applied in detection 
of very long-chain fatty acids in form of picolinyl esters coming from sugar cane wax [102]. HPLC-MS coupled with three ionization systems, electron impact (EI), atmospheric pressure chemical ionization, and electrospray ionization, was suitable for the accurate determination of PUFA and also their oxidative metabolites such as eicosanoids in biological samples in the range of pg [103]. According to papers prepared by Řezanka et al., which were focused on fatty acids analysis in lower organisms, liquid chromatography mass spectrometry coupled with ionization mode APCI was the most efficient method applied for identification and quantification of very long-chain polyunsaturated fatty acids from marine organisms (which have ability to produce VLCPUFA) such as marine dinoflagellates Amphidinium carterae and green algae Chlorella kessleri $[81,104-106]$ and also in oil obtained from Ximenia fruits (raw material for cosmetic industry) [107]. As it was performed in these papers HPLCMS-APCI system consisted of Hichrom column (HIRPB-250AM) and gradient solvent program with acetonitrile $(\mathrm{MeCN})$, dichloromethane (DCM), and propionitrile (EtCN) which were suitable for separation 13 of picolinyl esters of VLCPUFA from lower organisms. Excellent separation of methyl esters of unsaturated fatty acids coming from freshwater crustacean was achieved by the same mobile phase and the chromatographic column packed with octadecylsilyl phase (Supelcosil LC-18) [108]. An extensive review of a very long polyunsaturated published by Řezanka and Sigler indicates that the modern analytical methods such as HPLCMS make the detection and identification of VLC-PUFA possible in different classes of lipids including microbial kingdoms and fungi [109]. Reversed-phase HPLC with gradient elution of solvent system containing acetonitrile and chloroform and equipped with light-scattering detector (ELSD) was used to purify and identify the methyl esters of C16C28 PUFA including octacosaoctaenoic acid in milligram quantities from marine microalgae [82]. A simple method based on reversed-phase ion-pair high performance liquid chromatography (RP-HPLC) was used successfully to separate the various monoepoxides of eicosatrienoic, arachidonic, eicosapentaenoic, and docosahexaenoic acids [110]. These compounds were easily identified by liquid chromatography mass spectrometry (HPLC-MS) with atmospheric pressure chemical ionization (APCI) in nanogram range [110]. This work demonstrated that the method based on APCI-MS coupled with HPLC is highly reliable for the analysis of various monoepoxides of PUFA in their metabolism study. Another HPLC system such as nonaqueous reversed-phase high performance liquid chromatography (NARP-HPLC) with atmospheric pressure chemical ionization (APCI-MS) was suitable for detection of 5 unsaturated polymethylene interrupted fatty acids such as cis-5,9-octadecadienoic (taxoleic), cis-5,9,12-octadecatrienoic (pinolenic), cis-5,11-eicosadienoic (keteleeronic), and cis-5,11,14-eicosatrienoic acids (sciadonic) isolated from conifer seed oils (obtained from European Larch, Norway Spruce, and European Silver Fir) [111]. Combination of two chromatographic methods such as TLC and HPLC was used to analyze n-3 fatty acids in fish oil dietary supplements. The EPA and DHA fraction obtained by means of Ag-TLC method were further analyzed by HPLC.
The chromatographic column ODS $(3.9 \mathrm{~mm} \times 30 \mathrm{~cm}, 10 \mu \mathrm{m})$, mobile phase containing tetrahydrofuran-acetonitrile-wateracetic acid 25:35:75:0.4(v/v/v/v), and photodiode array detector in the range of $190-240 \mathrm{~nm}$ were used in this analysis [112]. HPLC system equipped with analytical column Supelcosil C18 $(4.6 \mathrm{~mm} \times 25 \mathrm{~cm})$ and photodiode array detector (DAD) was used for the analysis of hydroperoxy PUFA as the products of peroxidation coming from human plasma. A mixture of acetic acid-acetonitrile-tetrahydrofuran $52: 30: 18(\mathrm{v} / \mathrm{v} / \mathrm{v})$ as mobile phase was used. The analysis was monitored at $200-300 \mathrm{~nm}$. Quantity control by applied procedure of obtained derivatives of PUFA may be useful as clinical markers of oxidative stress on biological systems [113]. In another paper gradient reversed-phase liquid chromatography (C18 ODS $25 \mathrm{~cm} \times 0.46 \mathrm{~cm}, 5 \mu \mathrm{m}$ ) by use of methanol water and universal ELSD detector allowed for separation and fractionation of saturated, unsaturated, and oxygenated free fatty acids as methyl esters extracted from seeds of Crepis alpina and Vernonia anthelmintica, respectively [114]. This work showed that reversed-phase C18 was suitable for purification and fractionation of PUFA before their quantification by GC-MS. Besides HPLC system equipped with above-mentioned types of detector modes such as ECD, MS, ELSD, DAD, and UV, a fluorescence detector is also very useful $[115,116]$ which enabled precise determination of long-chain polyunsaturated fatty acids including linolenic, arachidonic, eicosapentaenoic, and docosahexaenoic acids in human serum at low concentrations like fmoles. For example, the method described in 1986 by Yamaguchi et al. performed the conversion of LC-PUFA into fluorescent derivatives by reaction with 3-bromomethyl-6,7-dimethoxy-1-methyl$2(1 \mathrm{H})$-quinoxalinone. Separation process was performed on a reversed-phase column (YMC Pack C8) with an isocratic elution using aqueous $72 \%(\mathrm{v} / \mathrm{v})$ acetonitrile [115]. Current literature shows that HPLC with different solvent systems is suitable in analysis of novel hydroxyl fatty and phosphoric acid esters of 10-hydroxy-2-decenoic acid (9-HAD) coming from the royal jelly of honeybees (Apis mellifera). HPLC analysis was carried out on Diaion HP-20, Sephadex LH-20, and Cosmosil 75C18-OP column systems. Different mobile phases containing acetonitrile were applied. A refractive index detector was applied to monitor the elution profile of examined fatty acids [117].

\subsection{Silver Ion HPLC in Quantification and Identification} of Geometric Isomers of Fatty Acids. As it was reported by Nikolova-Damyanova and Momchilova [118], silver ion HPLC (Ag-HPLC) is widely applied by many scientists as a preliminary step for the fractionation of complex mixture of fatty acids into their groups prior to quantitative analysis by GC method. Resolution of fatty acids by means of AgHPLC is achieved according to the number and geometry of double bonds [118]. Separation is based on the reversible formation of a weak charge-transfer complex between a silver ion and a double bond. The main problem in Ag-HPLC is introduction of $\mathrm{Ag}^{+}$into this system. Thus, similar to the case of Ag-TLC the first attempt was performed on column which was laboratory packed with slurry of the stationary phase (e.g., silica gel) impregnated with $\mathrm{AgNO}_{3}$. Second method is 
to add silver ion solution $\left(\mathrm{AgNO}_{3}\right)$ into mobile phase. Third method is to use commercially available silica based cation exchange column (Nucleosil 5 SA), or the column which is produced by Chrompack (ChromSpher 5 lipids). These commercial column systems give much better results (better reproducibility) of fatty acids analysis than those laboratory prepared [118]. Another excellent review of the chromatographic methods used to analyze geometrical and positional isomers of fatty acids by Aini et al. [119] showed that the following factors affect resolution of fatty acids in silver ion HPLC such as the impregnation method of column, mobile phase composition, and also column temperature [119]. The choice of mobile phase composition used in Ag-HPLC is usually toluene based, acetonitrile based, hexane based, or dichloromethane based [118, 120]. Good results have been achieved by the use of isopropanol and tetrahydrofurane as a modifier. The lower column temperature generally results in shorter elution time in Ag-HPLC. Moreover, the improvement in resolution of monoenoic and polyenoic fatty acids was obtained by converting them into phenacyl, benzyl, n-propyl, n-butyl, and ethyl isopropyl esters [52]. Separation by Ag-HPLC coupled with UV detector of cisand trans-octadecanoic acids described by Momchilova and Nikolova-Damyanova [83] indicated that the efficiency of the separation increases in the following order: phenethyl < phenacyl $<$ p-methoxyphenacyl esters. Yet, retention and resolution of these fatty acids by Ag-HPLC could be affected by small changes of dichloromethane in mobile phase. Among various chromatographic systems the best resolution of cisand trans-positional isomers of octadecenoic acid after converting them into $\mathrm{p}$-methoxyphenacyl esters was achieved on a silver ion column by isocratic elution with a mobile phase containing hexane-dichloromethane-acetonitrile in volume composition of $60: 40: 0.2(\mathrm{v} / \mathrm{v} / \mathrm{v})$ [120]. Similar mobile phase was used by Momchilova and Nikolova-Damyanova in 2000 to estimate the chromatographic properties of positional isomers of octadecenoic fatty acids after conversing them to 2-naphthyl, 2-naphthylmethyl, and 9-anthrylmethyl derivatives [83]. According to the results obtained in this paper, dichloromethane-acetonitrile $100: 0.025(\mathrm{v} / \mathrm{v})$ as mobile phase provided better resolution of 9-anthrylmethyl derivatives of 6-, 9-, and 11-18:1. High resolution by AgHPLC was obtained for the positional isomers of PUFA such as eicosapentaenoic acid, docosahexaenoic acid, and also docosapentaenoic acid coming from triacylglycerols containing PUFA. The hexane-isopropanol-acetonitrile solvent system was suitable for the separation of these compounds [84]. Isolation of some PUFA from edible oils by argentate silica gel chromatography (Ag-TLC and Ag-HPLC) was performed by Guil-Guerrero et al. [121]. Using this method the isomers of the following fatty acids, linoleic acid, $\alpha$-linolenic, $\gamma$-linolenic, and stearidonic acid, and eicosapentaenoic and docosahexaenoic acid, have been isolated in form of methyl esters from linseed, sunflower, and borage seed oils and from shortfin mako liver oil. Similarly, like it was described in the previous part, Ag-HPLC was useful for analysis of eicosapentaenoic and docosahexaenoic acid geometrical isomers formed during fish oil deodorization [63]. Obtained results showed that this technique cannot be used to determine the isomers in fish oil which have been formed at the temperature higher than $180^{\circ} \mathrm{C}$ (e.g., at $\left.220^{\circ} \mathrm{C}\right)$, because the interference between obtained isomers, especially di-trans DHA and all-cis EPA, was observed. Efficient analysis of trans isomers of conjugated linoleic acid in synthetic and animal products (from pigs, chicken meat) was achieved also by chromatographic techniques including Ag-HPLC [62]. Recent literature indicates that quantification of separated by AgHPLC geometric isomers of fatty acids is mainly performed by GC-MS or by GC coupled with FID (flame-ionization detector). FID, UV, and refractive detector are usually used for direct quantification of isomers of fatty acids as methyl esters. As it was reported by Nikolova-Damyanova and Momchilova [118] aromatic esters of fatty acids can be detected by Ag-HPLC combined with UV-VIS detector in the range of $0-200 \mu \mathrm{g}$. The paper prepared in 2013 by Sun and coworkers demonstrates that a liquid chromatography/inline ozonolysis/mass spectrometry $\left(\mathrm{LC} / \mathrm{O}_{3}-\mathrm{MS}\right)$ is a practical and easy to use new approach to direct determination of double bond position in lipids presented in complex mixture. In order to test this method in complex lipid extracts, a sample of bovine fat with known amount of positional isomers and cis/trans isomers of unsaturated fatty acids was analyzed. The main advantage of the in-line ozonolysis is its applicability in combination with various mass spectrometers without instrumental modification [122].

Survey of some selected HPLC conditions useful for separation and identification of MUFA and PUFA from various samples is listed in Table 2.

\section{Gas Chromatography (GC)}

Among different chromatographic methods such as TLC or HPLC, which are described in detail in this paper, gas chromatography (GC) is the most popular for fatty acids analysis. As it was reported by Casal and Oliveira, GC analysis of fatty acids is the first chromatographic method known in fatty acids analysis for 60 years [123]. From this time to 2002 year numerous original and review papers were performed with emphasis on a gas chromatographic analysis of the common and uncommon fatty acids [85, 123-125].

The aim of our work was to describe present-day GC analysis of fatty acids belonging to mono- and polyunsaturated group (MUFA and PUFA), whose biological significance has increased in recent years. This paper was prepared on the basis of the papers coming from the last decade (2002-2013).

4.1. Derivatization Methods for GC Analysis of Fatty Acids. The main step in GC analysis of fatty acids is the process of conversion of these compounds into suitable volatile derivatives [123]. The most frequently applied derivatives are alkyl derivatives (methyl-, ethyl-, and isopropyl-) obtained by means of esterification of fatty acids. This procedure facilitates volatility of fatty acids and also improves their separation and sensitivity to GC detectors. For this aim, the following esterification methods are applied [123]: methylation catalyzed by $\mathrm{H}^{+}$, esterification catalyzed by $\mathrm{OH}^{-}$, esterification with benzyl alcohol (p-bromobenzyl, p-methylbenzyl, and p-nitrobenzyl iodide), methylation with diazomethane in 


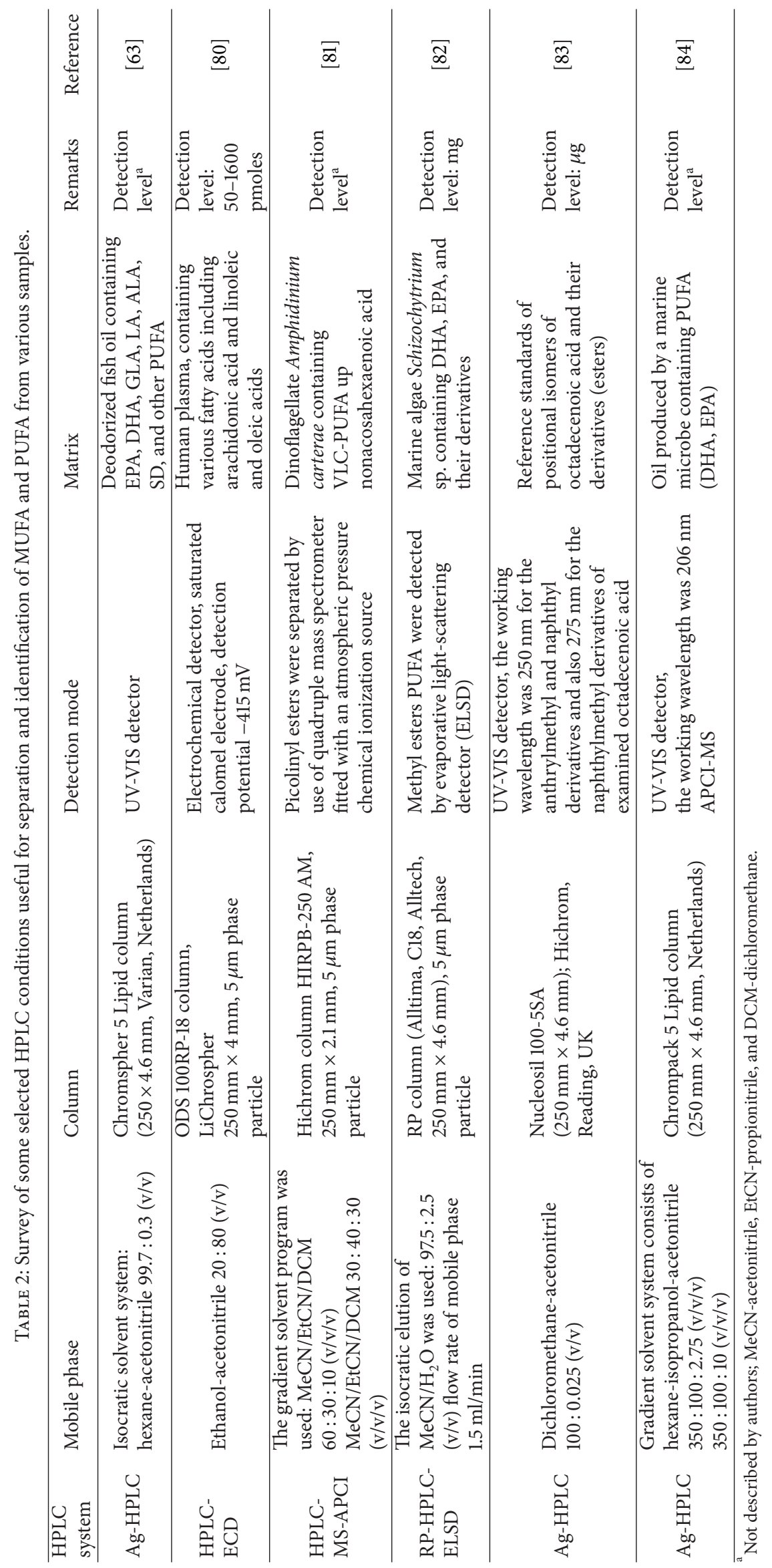


ethereal solution, or with boron trichloride $\left(\mathrm{BCl}_{3}-\mathrm{MeOH}\right)$, methylation by means of tetramethylammonium (TMAH) hydroxide or trimethylsulfonium hydroxide (TMSH), derivatization with tert-butyldimethylsilyl (tBDMSi) or dimethyloxazolidine (DMOX), and also cyanomethyl derivatization.

Among the above-presented derivatization procedures the most important for GC-MS analysis of mono- and polyunsaturated fatty acids are DMOX derivatives and picolinyl derivatives which are widely applied for the determination of double sites in unsaturated fatty acids. A rapid and inexpensive method for separation of very long-chain fatty acids is cyanomethyl derivatization.

4.2. Instrumentation of GC. In gas chromatography of fatty acids, a variety of columns with different properties such as polar and nonpolar are available. Of all the most frequently applied in fatty acids analyses are the polar columns. The fused silica columns allow improvements in the separation of PUFA, for example, from fish oil samples. Another type of stationary phases used for fatty acids analysis is polar polyesters such as Carbowax column, for example, PEG (polyethylene glycol) which is commercially available as Carbowax-20 M, CP-Wax 52CB, DB-Wax, and so forth. Next example of polar stationary phase used in GC is cyanopropyl polysiloxane such as commercially available HP-88, CP-Sil88, BPX70, SP2340, and SP-2560. As it was described in Casal and Oliveira report [123], the high polarity of the cyanosilicone phases allows the separation of geometrical isomers (cis and trans) of mono- and polyunsaturated fatty acids [123]. The literature review indicates that packed GC columns (glass tubing) with stationary phase containing usually from 6 to $5 \mathrm{~mm}$ diameters are still in use in fatty acid analysis. Among them the most popular is Chromosorb series. Others, which belong to polar stationary phases, are organosilicon polyesters (EGSS-X), butanediol succinate (BDS), and diethylene glycol succinate (DECS) $[121,123]$.

Of different GC detectors which show high sensitivity (from nanograms to femtograms) such as NPD (nitrogen phosphorus-sensitive detector), FDP (flame photometric detector), ELCD (electrolytic conductivity detector), and PID (photoionization detector), FID (flame ionization detector) and also mass detector (MS) are commonly used in fatty acids analysis [124]. FID allows detecting the organic substances including unsaturated fatty acids mono- and poly- in picograms. The carrier gases used in this method are nitrogen, helium, and hydrogen. GC-MS detection is a powerful tool in GC analysis of fatty acids (saturated and unsaturated) coming from different sources such as sea water, wood, and fish oil. The fact that MS is suitable for the localization of double bond in polyunsaturated fatty acids is important. An efficient detection method in study of very long-chain fatty acid esters in biological sample (blood, urine) and wax is tandem spectrometry MS/MS [18]. Recently, a novel trend in GC detection is coupling two different detectors in parallel to the outlet of column, for example, FID-ELCD. Moreover, application of GC analysis with FT-IR or NMR technique can facilitate the determination of functional groups and structural studies of fatty acids in the case of their geometrical isomers [18].
4.3. GC-Mass Spectrometry (GC-MS) of Fatty Acids. Besides GC-FID, mass spectrometry coupled to GC (GC-MS) is the most powerful tool for identification of mono- and polyunsaturated fatty acids. This technique requires derivatization of them into picolinyl esters, pyrrolidines, or 4,4dimethyloxazolidines derivatives, respectively [123]. Casal and Oliveira confirmed that the picolinyl esters are very suitable in MS analysis of MUFA and PUFA because they offer a specific mass fragmentation pattern [123]. In 2005 Destaillats et al. have shown that methyl ester derivatives used for routine quantification by GC-FID can be also used for structural investigation by GC-MS of long-chain polyunsaturated fatty acids (e.g., metabolites of rumelenic acid) [85]. An improved method of GC-MS for the identification of very long-chain highly unsaturated fatty acids with more than 22 carbon atoms $\left(\mathrm{C}_{28}\right)$ such as octacosaheptaenoic acid (28:7, $\mathrm{n}-6)$ and octacosaoctaenoic acid $(28: 8, \mathrm{n}-3)$ in seven marine dinoflagellate species was developed by Monsour et al. [86]. In another work, the total lipids of three crustacean species coming from Lake Baikal were analyzed for long-chain polyunsaturated fatty acids such as $24: 3(\mathrm{n}-6), 24: 3$ (n3), $24: 5(\mathrm{n}-3), 26: 3(\mathrm{n}-6), 26: 5(\mathrm{n}-6)$, and also $28: 7$ (n6) by use of Ag-TLC and GC-MS [87]. In further study, automated GC-MS was applied to identify polyunsaturated fatty acids in algal and microbial cultures (some freshwater algae and in filamentous cyanobacterium). A novel GCMS method developed by Akoto et al. in 2005 enabled detection the polyunsaturated fatty acids after their previous derivatization into corresponding methyl esters. By means of the described method unique PUFA in some green algae and cyanobacterium, which play a role of biomarkers in ecological and food studies, can be determined [88]. Another work demonstrated that GC-MS can be successfully used for quantitative analysis of total n-3 and n-6 fatty acids in human plasma. Six PUFA were esterified and next quantified by the use of GC-MS and also by means of reference spectrophotometric method. GC analysis was performed on DB23 fused silica column $(30 \mathrm{~m} \times 0.32 \mathrm{~mm}, 0.25 \mathrm{~mm})$. Helium was applied as carrier gas. This study showed that applying of GC-MS in quantification of PUFA (n-3 and n-6) gives the results with the high accuracy. In addition, the statistical evaluation of both analytical methods indicated that there is no significant difference between GC-MS and spectrophotometric method [126]. In the next paper, the content of seventy-two unsaturated fatty acids (polyenoic) present in mantle, muscle, and viscera of the marine bivalve Megangulus zyonoensis was determined [127]. The GC analysis coupled to FID was performed on capillary column (Supelco, $30 \mathrm{~m} \times$ $0.32 \mathrm{~mm}, 0.25 \mathrm{~mm}$ ). Helium was used as carrier gas at a flow rate of $1.5 \mathrm{~mL} / \mathrm{min}$. DMOX derivatives of examined fatty acids were analyzed by means of GC-MS equipped also with Omegawax-320 capillary column (Supelco, $30 \mathrm{~m} \times$ $0.32 \mathrm{~mm}, 0.25 \mathrm{~mm}$ ). The spectra were recorded at ionization energy of $70 \mathrm{eV}$. Another example indicates the usefulness of GC-MS in analysis of a new octadecatrienoic acid as a component of Chrysanthemum zawadskii Herb. (seed oil). To confirm the structure of the new unusual fatty acids different chemical derivatizations (preparation of methyl esters, pyrrolidine, picolinyl esters, and dimethyloxazolidine 
derivatives) were applied [128]. Capillary GC analysis was carried out using GC chromatograph equipped with FID and a $50 \mathrm{~m} \times 0.25 \mathrm{~mm}$ column CP-Sil 88 by means of hydrogen as a carrier gas at a flow rate of $2 \mathrm{~mL} / \mathrm{min}$. GC-MS analysis of fatty acid derivatives were performed on silica fused column Supelcowax $10(30 \mathrm{~m} \times 0.25 \mathrm{~mm}, 0.25 \mu \mathrm{m})$. Helium was used as a carrier gas [128]. The reviewed papers showed that a rapid GC-MS method is the most frequently used technique for the quantification and identification of geometric isomers of long-chain PUFA including CLA [129]. A series of CLA with double bond positions with all possible geometries (cis/trans, trans/cis, cis/cis, and trans/trans) were converted into methyl esters and next chromatographically analyzed in the low femtomole range for diagnostic purpose (in clinical study) [130]. Performed GC method should be more accurate to direct quantification of total trans-octadecenoic acid in food samples (e.g., milk). Results presented by Destaillats et al. [131] confirmed that the isomeric profile of transoctadecenoic acid in milk fat determined by GLC in combination with Ag-TLC may be found as the reference method.

The recently published paper by Liu and coworkers indicates that among various analytical techniques GC-MS method using newer generation of detection system such as single quadrupole mass detector is high sensitive new tool for studies of n-3/n-6 PUFA in small samples of human and mouse retina. These studies suggest that the method developed by Liu et al. could be satisfactorily applied in the treatment of the pathological process of macular degenerations and dystrophies [132].

4.4. GC-FID Analysis (Gas Chromatography Coupled with Flame Ionization Detector) of Fatty Acids. The current research shows that flame ionization mode of detection is the most common analytical method used in routine quantitative analysis of fatty acids in various matrices, because it is robust and of low cost in comparison with mass spectrometry [123]. The studies conducted by Schreiner confirmed the accuracy and robustness of GC-FID technique for quantification of LC-PUFA [133]. In order to check the robustness of gas chromatographic method in combination with FID for quantification of PUFA, various chromatographic systems were used by Schreiner. Thus, this work is a guideline which explains how to achieve the accuracy 17 and robustness of GC-FID method. During the last decade there is an increase in the application of GCFID in monitoring of omega-3 and omega- 6 fatty acids in various matrices samples including human and nutritional. According to Böcking and coworkers PUFA including the two presented above fatty acids and linoleic acid could be satisfactorily quantified using GC-FID in serum for clinical diagnosis (e.g., in case of cardiovascular diseases) and in quality control of food, for example, cow's milk [89]. Another example of application of GC-FID in analysis of biological samples shows the paper performed by Bláha et al. [134]. The described GC-FID study of selected MUFA and PUFA (e.g., CLA, EPA, and DHA) and their metabolites were analyzed in human blood under the following conditions: fused silica capillary column SP2330 (30 m $\times$ $0.25 \mathrm{~mm}$ ), helium as a carrier gas, and temperature of column in the range from $120^{\circ} \mathrm{C}$ to $230^{\circ} \mathrm{C}$. The developed method plays a significant role in coronary atherosclerosis study. Quantitative aspect of GC-FID bioanalysis of PUFA in plasma lipoproteins was also widely described by Tvrzická and coworkers [135]. Novel possibilities in GC-FID analysis are to use this technique for determining of medium and long-chain polyunsaturated fatty acids in clinical (parenteral) formulations [136]. The data presented in this paper indicate that GC-FID can be easily used for accurate determination of PUFA composition in lipid emulsion. Most of the papers regarding the use of gas chromatography for analysis of polyunsaturated fatty acids such as linoleic acid and their geometrical isomers present in dairy fat (e.g., milk fat) recommend the column type Carbowax such as Supelcowax 10 [137]. The main advantage of this column is a better resolution of the linolenic and eicosadienoic acid isomers [137]. Kramer and Cruz-Hernandez and their coworkers indicated that besides polyethylene glycol capillary column, 100-m CP-Sil 88 column (100\% cyanopropyl polysiloxane) could be very suitable in PUFA analysis including CLA isomers in milk fat $[76,137]$. Both helium and hydrogen were used as the carrier gases, respectively. Gas chromatograph was equipped with FID. The profile of polyunsaturated fatty acids especially trans isomers in food samples is usually analyzed by gas chromatography. The official method recommends the use of fatty acids in form of methyl esters [138]. In 2000 Timmins and coworkers developed a method for quantification of omega-3 from marine oils as ethyl esters. This analysis was conducted with gas chromatograph coupled with FID on an Omegawax 320 fused silica capillary column $(30 \mathrm{~m} \times$ $0.32 \mathrm{~mm}, 0.25 \mu \mathrm{m}$ ). The carrier gas was helium at a pressure $63 \mathrm{kPa}$ [139]. Profile of polyunsaturated trans fatty acids in food products (e.g., peanut oil) including preparation of fatty acid methyl esters was successfully determined with a highly polar column CP-Sil 88. Moreover, the methylation procedure allows accurate isolation of geometrical isomeric of linolenic acid [140]. Tyburczy et al. studied the trans polyunsaturated fatty acids in selected fast food such as hamburger, pizza, chicken, cheese, and others [90]. This fact shows usage of GC-FID method in monitoring of the trans fatty acid level in some restaurant foods. The current research indicates the usefulness of GC-FID in quantification of some mono- and polyunsaturated fatty acids (e.g., oleic, linoleic, and linolenic) in oils of wheat germ and seeds produced as by-products [91]. The content of long-chain polyunsaturated fatty acids like eicosapentaenoic acid and docosahexaenoic acid in different assortments of smoked Atlantic mackerel and Baltic sprats was determined by the use of gas chromatograph equipped with FID [92]. The results demonstrate that the applied GC-FID system is a powerful analytical tool in control of the PUFA content in sprats smoked fish which are the source of n-3 and n- 6 fatty acids. A recent paper has shown GC-FID determination of fatty acid methyl esters in biodiesel bland using an ionic liquid stationary phase [141]. In this work the two 1,9-di(3-vinyl-imidazolium)nonane bis(trifluoromethyl)sulfonylimidate stationary phase capillary columns SLB-IL-100 $(30 \mathrm{~m} \times 0.25 \mathrm{~mm}, 0.25 \mu \mathrm{m})$ and on SLB-IL-100 $(12 \mathrm{~m} \times 0.10 \mathrm{~mm}, 0.08 \mu \mathrm{m})$ have been evaluated to determine the profile of fatty acids including eicosanoic, linoleic, oleic, and linolenic in biodiesel blend. 
4.5. Gas Chromatography in Analysis of Geometrical and Positional Isomers of Fatty Acids. As it was described in previous section regarding TLC and HPLC methods, the analysis of geometrical isomers and position of double bonds may give a great impact on nutritional study, especially in food quality control. To obtain good results in analysis of geometrical isomers of mono- and polyunsaturated fatty acids, they should be converted into suitable derivatives. To determine the number of double bonds the GC equipped with MS detector is enough [119]. Among various derivatives, those which ensure good results in identification of double bond position by GC-MS technique are 4,4-dimethyloxazolidine (DMOX) derivatives and picolinyl esters [119]. In the case of monoenoic acids conversion into dimethyl disulphide is satisfactory. In addition, identification of fatty acids double bond position is possible by GC coupled with MS/MS detector which requires the derivatization of the fatty acids into proper compounds, for example, PTSA derivatives (p-toluenesulfonic acid derivatives) [142]. To the most popular stationary phases which enable satisfactory resolution and positional characteristic of double bonds in unsaturated fatty acids belongs cyanopropyl capillary column such as CP-Sil 88 in case of MS/MS detection or Supelco 2560 capillary column which is suitable for GC-FID analysis [141].

4.6. GC $\times G C$ (Two-Dimensional Gas Chromatography). Two-dimensional gas chromatography is a new chromatographic technique which recently plays a very important role in resolution of fatty acids in complex samples such as lipids coming from marine biota (e.g., algae). According to Casal and Oliveira, the separation process by two-dimensional gas chromatography (2D-GC) is carried out on the two columns with different polarity [123]. For example, in $2011 \mathrm{Gu}$ and coworkers performed a comprehensive two-dimensional analysis of fatty acids including PUFA in marine biota [143]. The results described in this paper show that, in GC $\times$ GC method using an apolar polydimethylsiloxane $\times$ polar ionic liquid column combination, an excellent resolution of unsaturated fatty acids complementary to GC-MS identification was achieved. Another work performed by Manzano and coauthors [144] confirmed that GC $\times$ GC system using an apparatus equipped with capillary flow technology and a FID has been satisfactorily used to separate a large number of fatty acids including the eight isomers of the linolenic acid and also the linoleic isomers. All examined fatty acids were obtained from broccoli leaves by use of supercritical fluid extraction (SFE). The results of this experiment showed that SFE technique and GC $\times$ GC analysis with FID or MS detector are suitable to study fatty acids [144]. The current literature in emphasis on mono- and polyunsaturated fatty acids analysis in different matrix indicates that besides the widely used chromatographic techniques such as TLC, HPLC, and GC equipped with various detectors, the relatively new method is gas chromatography coupled to isotope ratio mass spectrometer (known as IRMS) [145]. As it was reported by Meier-Augenstein [145], this technique may be used in fatty acids analysis in complex biological samples and it is alternative to the typical detection systems applied in chromatographic analysis. Another new solution in gas chromatographic analysis of unsaturated fatty acids is to use GC in combination with infrared spectroscopy based on transmission (GC-IR) or on attenuated reflection (GC-ATR) [146]. Both techniques are refined in quantification of trans fatty acids in food products (margarines, vegetable oils).

Survey of some selected GC conditions useful for separation and identification of some MUFA and PUFA from different matrices is listed in Table 3.

\section{Supercritical Fluid Chromatography (SFC)}

A brief review of the chromatographic studies of LC-MUFA and LC-PUFA indicated that, among traditional GC technique and HPLC method, an alternative or complementary method to both of the mentioned techniques is supercritical fluid chromatography (SFC). Supercritical fluid chromatography is known as hybrid of gas and liquid chromatography. In contrast to GC and HPLC, SFC allows the use of higher flow rates, low temperature, no derivatization, and also universal detectors such as FID, ELSD, or MS [147]. This method leads to greater efficiency in short time analysis times and reduced consumption of organic solvents. Moreover as was accurately described by Señoráns and Ibañez [148] it permits the separation and determination of thermally labile (e.g., polyenic fatty acids), low volatile, and polar fatty acids (e.g., hydroxy fatty acids) which cannot be analyzed by HPLC or GC without derivatization. For this reason, in the last few years the use of SFC in fatty acid analysis has attracted increasing interest in the food sector [147, 148].

Supercritical fluid chromatography was usually performed with pure carbon dioxide $\left(\mathrm{CO}_{2}\right)$ as the mobile phase. Nowadays SFC is often carried out in subcritical conditions, and in many cases $\mathrm{CO}_{2}$ is modified with an organic solvent in order to increase the solubility of polar compounds [147-149].

SFC separation of fatty acids has been performed by means of different chromatographic columns, such as open tubular, packed, and packed capillary. The open tubular columns are preferred for separations when high efficiencies are required and also for complex samples [147-149].

Different detection modes are applied in SFC analysis such as UV-VIS detectors, ELSD (evaporative light scattering detector), and MS detector (mass spectrometer), but the most widely used in SFC is MS detector. It was stated that SFC analysis combined with MS detector provided very good levels of sensitivity. Similar to liquid chromatography (HPLCMS), atmospheric pressure chemical ionization (APCI) and electrospray ionization (ESI) are the most popular ionization methods recommended for SFC-MS analysis. Moreover, there is no limitation of mass analyzer that could be coupled to SFC system [147-149].

All important parameters such as mobile phase composition, columns, and the detection mode systems needed to SFC analysis of fatty acids were accurately described in review papers by Señoráns and Ibañez in 2002 and also by Bernal and coworkers in $2013[148,149]$. Excellent review study by Bernal et al. of the analysis of fatty acids in foods demonstrates that new trend in SFC analysis is SFC $\times$ SFC system. The use of two-dimensional SFC (2D-SFC) or SFC coupled to RPHPLC improves the separation of very complex mixtures. 


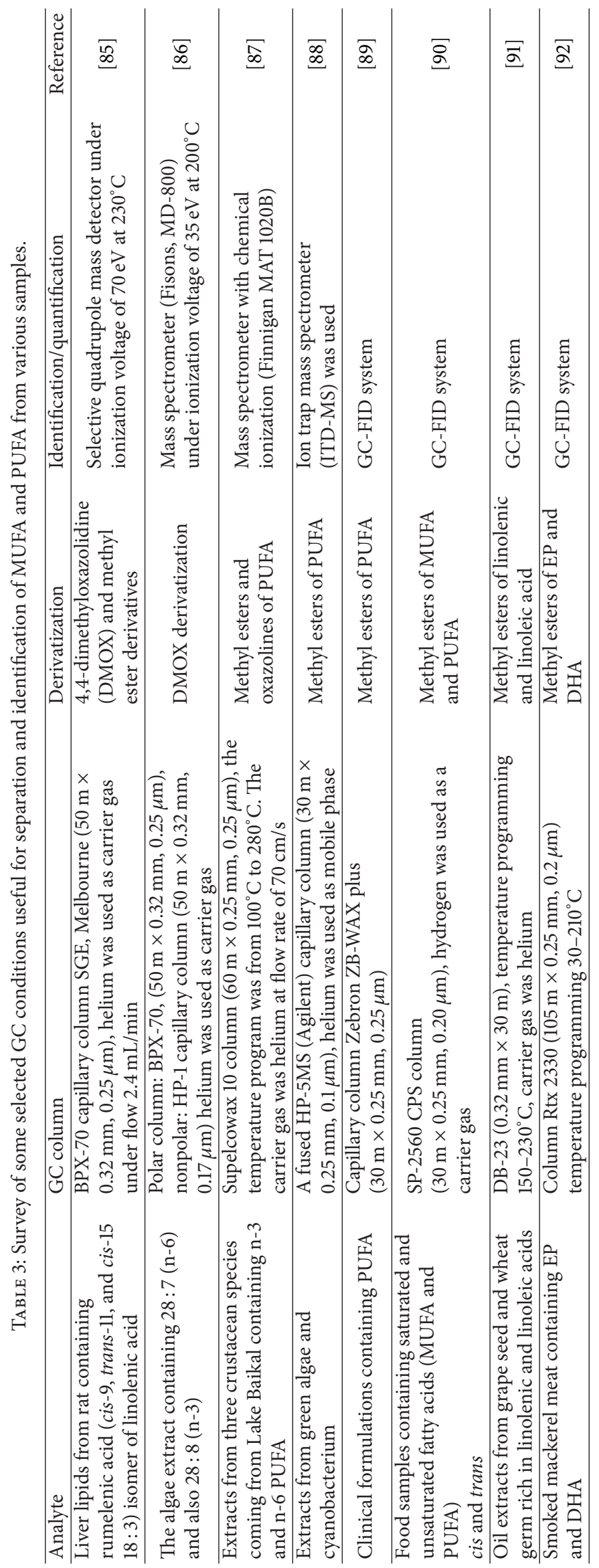


A preparative supercritical fluid chromatography was applied for PUFA separation to obtain enriched fractions of EPA from fish oil mixture. Silica gel as the stationary phase and carbon dioxide as the supercritical fluid were used. Under these conditions the best purity in EP-EE (eicosapentaenoic ethyl ester) reaches $95 \%$ with a $24.6 \%$ yield [149]. Recent metabolomic investigations show that the SFC-MS enables the simultaneous rapid analysis of lipids with varied structure. Applying cyanopropyl bonded silica gel-packed column the resolution of lipid mixture from the leaf of Catharanthus roseus resulted in satisfactory separation of lipid mixture with time less than 15 minutes. The data obtained in this study confirm that SFC system is a powerful tool for studies on lipid metabolomic because it is useful as a fingerprinting method not only for the screening of various lipids but also for the detailed profiling of their individual components $[150,151]$.

\section{Conclusions}

This literature review which is focused on the application of the chromatographic methods such as TLC, HPLC, GC, and also SFC in analysis of mono- and polyunsaturated fatty acids (MUFA, PUFA) in different matrices shows that all of the presented chromatographic methods are suitable in preseparation and quantification of these compounds. The choice of the chromatographic systems depends on the type of the sample to be analyzed and on the aim of chromatographic analysis (problem which should be solved by means of this technique). For instance, in order to obtain complete fractionation of "trans/cis" fatty acids from different samples, the traditional Ag-TLC or argentation HPLC (Ag-HPLC) is used. The column chromatography such as GC and HPLC may be used in further steps of chromatographic analysis of unsaturated fatty acids (MUFA and PUFA), especially to determine the quantity of separated fatty acids. In the case of geometrical isomers (cis and trans) and determining of the number and position of double bonds present in studied unsaturated fatty acids, Ag-HPLC and various GC systems are popular. Current literature indicates that the innovations which are implemented into chromatographic systems include modified stationary phases, new derivatizing agents for fatty acids, and also developing of novel detection systems allowing sensitive and reproducible fatty acid analysis from complex samples. Moreover, the new chromatographic systems combined with other instrumental methods such as MS, MS/MS, IR, or two-dimensional GC enable analysis of a large number of MUFA and PUFA in lower quantities, which is required, for example, in food analysis. The results presented in our paper confirm that the chromatographic methods are still a powerful tool in analysis of monoand polyunsaturated fatty acids.

\section{Conflict of Interests}

The authors declare no conflict of interests regarding the publication of this paper.

\section{Acknowledgments}

This research was financed by the Medical University of Silesia as part of statutory research in 2014 Project no. KNW$1-006 / \mathrm{N} / 4 / 0$.

\section{References}

[1] D. Voet and J. G. Voet, Biochemistry, John Wiley \& Sons, New York, NY, USA, 4th edition, 2010.

[2] R. Murray, K. M. Botham, P. J. Kennelly et al., Harper's. Illustrated Biochemistry, McGraw-Hill Education, Toronto, Canada, 29th edition, 2012.

[3] P. Risé, F. Marangoni, and C. Galli, "Regulation of PUFA metabolism: pharmacological and toxicological aspects," Prostaglandins Leukotrienes and Essential Fatty Acids, vol. 67, no. 23, pp. 85-89, 2002.

[4] A. Sellmayer and P. C. Weber, "Polyunsaturated fatty acids and cardiovascular risk: Interference at the level of gene expression," The Journal of Nutrition Health and Aging, vol. 6, no. 4, pp. 230236, 2002.

[5] L. Arab, "Biomarkers of fat and fatty acid intake," Journal of Nutrition, vol. 133, supplement 3, pp. 925S-932S, 2003.

[6] P. Benatti, G. Peluso, R. Nicolai, and M. Calvani, "Polyunsaturated fatty acids: biochemical, nutritional and epigenetic properties," Journal of the American College of Nutrition, vol. 23, no. 4, pp. 281-302, 2004.

[7] W. Karmally, "Balancing unsaturated fatty acids: what's the evidence for cholesterol lowering?" Journal of the American Dietetic Association, vol. 105, no. 7, pp. 1068-1070, 2005.

[8] O. Ozyilkan, D. Colak, Z. Akcali, and B. Basturk, "Olive: fruit of peace against cancer," Asian Pacific Journal of Cancer Prevention, vol. 6, no. 1, pp. 77-82, 2005.

[9] A. Lapointe, C. Couillard, and S. Lemieux, "Effects of dietary factors on oxidation of low-density lipoprotein particles," The Journal of Nutritional Biochemistry, vol. 17, no. 10, pp. 645-658, 2006.

[10] J. S. Perona, R. Cabello-Moruno, and V. Ruiz-Gutierrez, "The role of virgin olive oil components in the modulation of endothelial function," The Journal of Nutritional Biochemistry, vol. 17, no. 7, pp. 429-445, 2006.

[11] P. D. Biondo, D. N. Brindley, M. B. Sawyer, and C. J. Field, “The potential for treatment with dietary long-chain polyunsaturated n-3 fatty acids during chemotherapy," The Journal of Nutritional Biochemistry, vol. 19, no. 12, pp. 787-796, 2008.

[12] B. Koletzko, E. Lien, C. Agostoni, and et al, "The roles of longchain polyunsaturated fatty acids in pregnancy, lactation and infancy: review of current knowledge and consensus recommendations," Journal of Perinatal Medicine, vol. 36, no. 1, pp. 5-14, 2008.

[13] C. Ruggiero, F. Lattanzio, F. Lauretani, B. Gasperini, C. AndresLacueva, and A. Cherubini, " $\Omega-3$ polyunsaturated fatty acids and immune-mediated diseases: Inflammatory bowel disease and rheumatoid arthritis," Current Pharmaceutical Design, vol. 15, no. 36, pp. 4135-4148, 2009.

[14] J. T. Brenna, N. Salem Jr., A. J. Sinclair, and S. C. Cunnane, " $\alpha$-Linolenic acid supplementation and conversion to n-3 longchain polyunsaturated fatty acids in humans," Prostaglandins Leukotrienes and Essential Fatty Acids, vol. 80, no. 2-3, pp. 85-91, 2009. 
[15] P. A. Corsetto, G. Montorfano, S. Zava, I. E. Jovenitti, A. Cremona, and A. M. Rizzo, "Effects of n-3 PUFAs on breast cancer cells through their incorporation in plasma membrane," Lipids in Health and Disease, vol. 10, article 73, 2011.

[16] I. M. Berquin, I. J. Edwards, S. J. Kridel, and Y. Q. Chen, "Polyunsaturated fatty acid metabolism in prostate cancer," Cancer and Metastasis Reviews, vol. 30, no. 3-4, pp. 295-309, 2011.

[17] M. Kaczmarski, B. Cudowska, M. Sawicka-Żukowska, and A. Bobrus-Chociej, "Supplementation with long chain polyunsaturated fatty acids in treatment of atopic dermatitis in children," Advances in Dermatology and Allergology, vol. 30, no. 2, pp. 103107, 2013.

[18] I. Brondz, "Development of fatty acid analysis by high-performance liquid chromatography, gas chromatography, and related techniques," Analytica Chimica Acta, vol. 465, no. 1-2, pp. 1-37, 2002.

[19] J.-M. Kornprobst and G. Barnathan, "Demospongic acids revisited," Marine Drugs, vol. 8, no. 10, pp. 2569-2577, 2010.

[20] C. Bigogno, I. Khozin-Goldberg, S. Boussiba, A. Vonshak, and Z. Cohen, "Lipid and fatty acid composition of the green oleaginous alga Parietochloris incisa, the richest plant source of arachidonic acid," Phytochemistry, vol. 60, no. 5, pp. 497-503, 2002.

[21] M. A. Hossain, "Fish as source of n-3 polyunsaturated fatty acids (PUFAs), which one is better-farmed or wild?" Advance Journal of Food Science and Technology, vol. 3, no. 6, pp. 455-466, 2011.

[22] O. P. Ward and A. Singh, "Omega-3/6 fatty acids: alternative sources of production," Process Biochemistry, vol. 40, no. 12, pp. 3627-3652, 2005

[23] L. A. Copeman and C. C. Parrish, "Lipids classes, fatty acids, and sterols in seafood from Gilbert Bay, southern Labrador," Journal of Agricultural and Food Chemistry, vol. 52, no. 15, pp. 48724881, 2004.

[24] A. Gupta, C. J. Barrow, and M. Puri, "Omega-3 biotechnology: thraustochytrids as a novel source of omega-3 oils," Biotechnology Advances, vol. 30, no. 6, pp. 1733-1745, 2012.

[25] V. Manikan, M. Sahaid Kalil, M. H. Mohd Isa, and A. Abdul Hamid, "Improved prediction for medium optimization using factorial screening for docosahexaenoic acid production by Schizochytrium SP. SW1," American Journal of Applied Sciences, vol. 11, no. 3, pp. 462-474, 2014.

[26] D. S. Nichols, "Prokaryotes and the input of polyunsaturated fatty acids to the marine food web," FEMS Microbiology Letters, vol. 219, no. 1, pp. 1-7, 2003.

[27] A. Arjuna, "Production of polyunsaturated fatty acids by fungi: a review," International Journal of Pharma and Bio Sciences, vol. 5, pp. 931-954, 2014.

[28] S. Das, P. S. Lyla, and S. Ajmal Khan, "Fatty acid profiles of marine benthic microorganisms isolated from the continental slope of Bay of Bengal: a possible implications in the benthic food web," Ocean Science Journal, vol. 42, no. 4, pp. 247-254, 2007.

[29] J. E. Karr, J. E. Alexander, and R. G. Winningham, "Omega-3 polyunsaturated fatty acids and cognition throughout the lifespan: a review," Nutritional Neuroscience, vol. 14, no. 5, pp. 216$225,2011$.

[30] Y. Abe, M. Honsho, H. Nakanishi, R. Taguchi, and Y. Fujiki, "Very-long-chain polyunsaturated fatty acids accumulate in phosphatidylcholine of fibroblasts from patients with Zellweger syndrome and acyl-CoA oxidasel deficiency," Biochimica et Biophysica Acta: Molecular and Cell Biology of Lipids, vol. 1841, no. 4, pp. 610-619, 2014.
[31] K. Hama, T. Nagai, C. Nishizawa et al., "Molecular species of phospholipids with very long chain fatty acids in skin fibroblasts of Zellweger syndrome," Lipids, vol. 48, no. 12, pp. 1253-1267, 2013.

[32] M. P. Agbaga, N. A. Mandal, and R. E. Anderson, "Retinal very long-chain PUFAs: new insights from studies on ELOVL4 protein," Journal of Lipid Research, vol. 51, no. 7, pp. 1624-1642, 2010.

[33] M. I. Aveldano, "A novel group of very long chain polyenoic fatty acids in dipolyunsaturated phosphatidylcholines from vertebrate retina," Journal of Biological Chemistry, vol. 262, no. 3, pp. 1172-1179, 1987.

[34] L. D. Bennett, R. S. Brush, M. Chan et al., "Effect of reduced retinal VLC-PUFA on rod and cone photoreceptors," Investigative Ophthalmology \& Visual Science, vol. 55, no. 5, pp. 3150-3157, 2014.

[35] I. A. Butovich, "Lipidomics of human meibomian gland secretions: chemistry, biophysics, and physiological role of meibomian lipids," Progress in Lipid Research, vol. 50, no. 3, pp. 278 301, 2011.

[36] B. Nikolova-Damyanova, "Fatty acids: silver ion TLC", in Encyclopedia of Chromatography, J. Cazes, Ed., pp. 846-848, Taylor and Francis, New York, NY, USA, 3rd edition, 2010.

[37] J. C. Touchstone, "Thin-layer chromatographic procedures for lipid separation," Journal of Chromatography B: Biomedical Applications, vol. 671, no. 1-2, pp. 169-195, 1995.

[38] B. Nikolova-Damyanova, R. Velikova, and L. Kuleva, "Quantitative TLC for determination of the triacylglycerol composition of sesame seeds," Journal of Liquid Chromatography \& Related Technologies, vol. 25, no. 10-11, pp. 1623-1632, 2002.

[39] B. Nikolova-Damyanova, "Quantitative thin-layer chromatography of triacylglycerols. Principles and application," Journal of Liquid Chromatography and Related Technologies, vol. 22, no. 10, pp. 1513-1537, 1999.

[40] T. Nakamura, M. Fukuda, and R. Tanaka, "Estimation of polyunsaturated fatty acid content in lipids of aquatic organisms using thin-layer chromatography on a plain silica gel plate," Lipids, vol. 31, no. 4, pp. 427-432, 1996.

[41] B. Fuchs, R. Süß, K. Teuber, M. Eibisch, and J. Schiller, "Lipid analysis by thin-layer chromatography-a review of the current state," Journal of Chromatography A, vol. 1218, no. 19, pp. 27542774, 2011.

[42] J. Sherma, "Thin-layer chromatography in food and agricultural analysis," Journal of Chromatography A, vol. 880, no. 1-2, pp. 129-147, 2000.

[43] B. Fuchs, K. Teuber, A. Nimptsch et al., "Thin-layer chromatography with direct mass spectrometric analyte detectiona review of the progress achieved in the last five years," in HighPerformance Thin-Layer Chromatography (HPTLC), M. M. Srivastava, Ed., pp. 335-363, Springer, New York, NY, USA, 2011.

[44] B. Fuchs, A. Nimptsch, R. Süss et al., "The analysis of brain lipids by a directly coupled MALDI/TLC approach," Journal of AOAC International, vol. 91, pp. 1227-1236, 2008.

[45] S. Lobasso, P. Lopalco, R. Angelini et al., "Coupled TLC and MALDI-TOF/MS analyses of the lipid extract of the hyperthermophilic archaeon pyrococcus furiosus," Archaea, vol. 2012, Article ID 957852, 10 pages, 2012.

[46] B. Fuchs, "Analysis of phospolipids and glycolipids by thin-layer chromatography-matrix-assisted laser desorption and ionization mass spectrometry," Journal of Chromatography A, vol. 1259, pp. 62-73, 2012. 
[47] B. Fuchs, J. Schiller, R. Süß et al., "Analysis of stem cell lipids by offline HPTLC-MALDI-TOF MS," Analytical and Bioanalytical Chemistry, vol. 392, no. 5, pp. 849-860, 2008.

[48] B. Fuchs, J. Schiller, R. Süß, M. Schürenberg, and D. Suckau, "A direct and simple method of coupling matrix-assisted laser desorption and ionization time-of-flight mass spectrometry (MALDI-TOF MS) to thin-layer chromatography (TLC) for the analysis of phospholipids from egg yolk," Analytical and Bioanalytical Chemistry, vol. 389, no. 3, pp. 827-834, 2007.

[49] G. Dobson, W. W. Christie, and B. Nikolova-Damyanova, "Silver ion chromatography of lipids and fatty acids," Journal of Chromatography B: Biomedical Applications, vol. 671, no. 1-2, pp. 197-222, 1995.

[50] B. Nikolova-Damyanova, "Silver ion chromatography and lipids," in Advances in Lipid Methodology-One, W. W. Christie, Ed., pp. 181-237, The Oily Press, Ayr, UK, 1992.

[51] B. Nikolova-Damyanova and S. Momchilova, "Silver ion thinlayer chromatography of fatty acids. A survey," Journal of Liquid Chromatography and Related Technologies, vol. 24, no. 10, pp. 1447-1466, 2001.

[52] B. Nikolova-Damyanova, W. W. Christie, and B. Herslöf, "Mechanistic aspects of fatty acid retention in silver ion chromatography," Journal of Chromatography A, vol. 749, no. 1-2, pp. 47-54, 1996.

[53] S. Momchilova and B. Nikolova-Damyanova, "Stationary phases for silver ion chromatography of lipids: preparation and properties," Journal of Separation Science, vol. 26, no. 3-4, pp. 261-270, 2003.

[54] D. Nikolova, D. Antonova, I. Marekov, and B. NikolovaDamyanova, "Bis-methylene-interrupted octadecadienoic fatty acids in Bulgarian bovine butter fats," European Journal of Lipid Science and Technology, vol. 108, no. 3, pp. 212-217, 2006.

[55] R. Wilson and J. R. Sargent, "High-resolution separation of polyunsaturated fatty acids by argentation thin-layer chromatography," Journal of Chromatography A, vol. 623, no. 2, pp. 403-407, 1992.

[56] R. Wilson and J. R. Sargent, "Chain separation of monounsaturated fatty acid methyl esters by argentation thin-layer chromatography," Journal of Chromatography A, vol. 905, no. 1-2, pp. 251-257, 2001.

[57] D. S. Lin, W. E. Connor, D. P. Wolf, M. Neuringer, and D. L. Hachey, "Unique lipids of primate spermatozoa: desmosterol and docosahexaenoic acid," The Journal of Lipid Research, vol. 34, no. 3, pp. 491-499, 1993.

[58] E. H. Belarbi, E. Molina, and Y. Chisti, "A process for high yield and scaleable recovery of high purity eicosapentaenoic acid esters from microalgae and fish oil," Enzyme and Microbial Technology, vol. 26, no. 7, pp. 516-529, 2000.

[59] J. T. Dillon, J. C. Aponte, Y.-J. Tsai, and Y. Huang, "Thin layer chromatography in the separation of unsaturated organic compounds using silver-thiolate chromatographic material," Journal of Chromatography A, vol. 1251, pp. 240-243, 2012.

[60] J. M. Sowa and P. V. Subbaiah, "Variable recoveries of fatty acids following the separation of lipids on commercial silica gel TLC plates: selective loss of unsaturated fatty acids on certain brands of plates," Journal of Chromatography B, vol. 813, no. 1-2, pp. 159166, 2004.

[61] A. M. Shahin, M. K. McGuire, M. A. McGuire, K. L. Ritzenthaler, and T. D. Shultz, "Determination of $c 9$,t11 -CLA in major human plasma lipid classes using a combination of methylating methodologies," Lipids, vol. 38, no. 7, pp. 793-800, 2003.
[62] J. K. G. Kramer, C. Cruz-Hernandez, Z. Deng, J. Zhou, G. Jahreis, and M. E. R. Dugan, "Analysis of conjugated linoleic acid and trans 18:1 isomers in synthetic and animal products," The American Journal of Clinical Nutrition, vol. 79, no. 6, pp. 1137S-1145S, 2004.

[63] V. Fournier, P. Juanéda, F. Destaillats et al., "Analysis of eicosapentaenoic and docosahexaenoic acid geometrical isomers formed during fish oil deodorization," Journal of Chromatography A, vol. 1129, no. 1, pp. 21-28, 2006.

[64] E. Bailey-Hall, E. B. Nelson, and A. S. Ryan, "Validation of a rapid measure of blood PUFA levels in humans," Lipids, vol. 43, no. 2, pp. 181-186, 2008.

[65] J. Flieger, H. Szumiło, and K. Giełzak-Koćwin, “Optimizing modification conditions of silica gel with metal salts," Journal of Liquid Chromatography and Related Technologies, vol. 22, no. 19, pp. 2879-2894, 1999.

[66] D. Allan and S. Cockcroft, "A modified procedure for thin layer chromatography of phospholipids," Journal of Lipid Research, vol. 23, no. 9, pp. 1373-1374, 1982.

[67] W.-Q. Wang and A. Gustafson, "One-dimensional thin-layer chromatographic separation of phospholipids and lysophospholipids from tissue lipid extracts," Journal of Chromatography - Biomedical Applications, vol. 581, no. 1, pp. 139-142, 1992.

[68] J. L. Beneytout, D. Greuet, and M. T. Rigaud, "Separation of arachidonic acid metabolites by thin-layer chromatography using new silicone-bonded plates," Journal of High Resolution Chromatography, vol. 7, no. 9, pp. 538-539, 1984.

[69] J. Pikul and F. A. Kummerow, "Thiobarbituric acid reactive substance formation as affected by distribution of polyenoic fatty acids in individual phospholipids," Journal of Agricultural and Food Chemistry, vol. 39, no. 3, pp. 451-457, 1991.

[70] M. J. Martinez-Lorenzo, I. Marzo, J. Naval, and A. Pineiro, "Selfstaining of polyunsaturated fatty acids in argentation thin-layer chromatography," Analytical Biochemistry, vol. 220, no. 1, pp. 210-212, 1994.

[71] B. Fuchs and J. Schiller, "MALDI-TOF MS analysis of lipids from cells, tissues and body fluids," in Lipids in Health and Disease, P. J. Quinn and X. Wang, Eds., vol. 49 of Subcellular Biochemistry, pp. 541-565, Springer, Berlin, Germany, 2008.

[72] B. Fuchs, K. Arnold, and J. Schiller, "Mass spectrometry of biological molecules," in Encyclopedia of Analytical Chemistry, R. A. Meyers, Ed., pp. 1-39, John Wiley \& Sons, Chichester, UK, 2008.

[73] V. J. Sinanoglou, I. F. Strati, S. M. Bratakos, C. Proestos, P. Zoumpoulakis, and S. Miniadis-Meimaroglou, "On the combined application of Iatroscan TLC-FID and GC-FID to identify total, neutral, and polar lipids and their fatty acids extracted from foods," ISRN Chromatography, vol. 2013, Article ID 859024, 8 pages, 2013.

[74] A. Zabala, M. P. Portillo, M. T. Macarulla, V. M. Rodríguez, and A. Fernández-Quintela, "Effects of cis-9,trans-11 and trans10,cis-12 CLA isomers on liver and adipose tissue fatty acid profile in hamsters," Lipids, vol. 41, no. 11, pp. 993-1001, 2006.

[75] I. Marekov, S. Panayotova, and R. Tarandjiiska, "Fatty acid composition and seasonal variation of trans fatty acid content in Bulgarian butter fats by silver ion TLC and GC," Journal of Liquid Chromatography and Related Technologies, vol. 32, no. 9, pp. 1183-1195, 2009.

[76] C. Cruz-Hernandez, Z. Deng, J. Zhou et al., "Methods for analysis of conjugated linoleic acids and trans-18:1 isomers in 
dairy fats by using a combination of gas chromatography, silverion thin-layer chromatography/gas chromatography, and silverion liquid chromatography," Journal of AOAC International, vol. 87, no. 2, pp. 545-562, 2004.

[77] S. D. Krämer, J. A. Hurley, N. J. Abbott, and D. J. Begley, "Lipids in blood-brain barrier models in vitro I: thin-layer chromatography and high-performance liquid chromatography for the analysis of lipid classes and long-chain polyunsaturated fatty acids," In Vitro Cellular \& Developmental Biology-Animal, vol. 38, no. 10, pp. 557-565, 2002.

[78] A. Laffargue, A. de Kochko, and S. Dussert, "Development of solid-phase extraction and methylation procedures to analyse free fatty acids in lipid-rich seeds," Plant Physiology and Biochemistry, vol. 45, no. 3-4, pp. 250-257, 2007.

[79] G. Chinnasamy, P. J. Davis, and A. K. Bal, "Seasonal changes in oleosomic lipids and fatty acids of perennial root nodules of beach pea," Journal of Plant Physiology, vol. 160, no. 4, pp. 355365, 2003.

[80] A. Kotani, T. Fuse, and F. Kusu, "Determination of plasma free fatty acids by high-performance liquid chromatography with electrochemical detection," Analytical Biochemistry, vol. 284, no. 1, pp. 65-69, 2000.

[81] T. Řezanka, L. Nedbalová, and K. Sigler, "Odd-numbered verylong-chain polyunsaturated fatty acids from the dinoflagellate Amphidinium carterae identified by atmospheric pressure chemical ionization liquid chromatography-mass spectrometry," Phytochemistry, vol. 69, no. 16, pp. 2849-2855, 2008.

[82] M. P. Mansour, "Reversed-phase high-performance liquid chromatography purification of methyl esters of C16-C28 polyunsaturated fatty acids in microalgae, including octacosaoctaenoic acid [28:8(n-3)]," Journal of Chromatography A, vol. 1097, no. 12, pp. 54-58, 2005.

[83] S. Momchilova and B. Nikolova-Damyanova, "Silver ion high performance liquid chromatography of polynuclear aromatic derivatives of positionally isomeric octadecenoic fatty acids," Journal of Liquid Chromatography and Related Technologies, vol. 23, no. 9, pp. 1319-1330, 2000.

[84] J. J. Han, Y. Iwasaki, and T. Yamane, "Use of isopropanol as a modifier in a hexane-acetonitrile based mobile phase for the silver ion HPLC. Separation of positional isomers of triacylglycerols containing long chain polyunsaturated fatty acids," Journal of High Resolution Chromatography, vol. 22, pp. 357-361, 1999.

[85] F. Destaillats, J.-L. Sébédio, O. Berdeaux, P. Juanéda, and P. Angers, "Gas chromatography-mass spectrometry determination of metabolites of conjugated cis-9,trans-11,cis-15 18:3 fatty acid," Journal of Chromatography B: Analytical Technologies in the Biomedical and Life Sciences, vol. 820, no. 1, pp. 15-22, 2005.

[86] M. P. Mansour, J. K. Volkman, D. G. Holdsworth, A. E. Jackson, and S. I. Blackburn, "Very-long-chain (C28) highly unsaturated fatty acids in marine dinoflagellates," Phytochemistry, vol. 50, no. 4, pp. 541-548, 1999.

[87] T. Řezanka and V. M. Dembitsky, "Very long chain polyunsaturated fatty acids in crustacea of the order Bathynellacea," Biochemical Systematics and Ecology, vol. 27, no. 6, pp. 551-558, 1999.

[88] L. Akoto, R. Pel, H. Irth, U. A. T. Brinkman, and R. J. J. Vreuls, "Automated GC-MS analysis of raw biological samples: application to fatty acid profiling of aquatic micro-organisms," Journal of Analytical and Applied Pyrolysis, vol. 73, no. 1, pp. 6975, 2005.
[89] C. Böcking, W. A. Nockher, M. Schreiner, H. Renz, and P. I. Pfefferle, "Development and validation of a combined method for the biomonitoring of omega-3/-6 fatty acids and conjugated linoleic acids in different matrices from human and nutritional sources," Clinical Chemistry and Laboratory Medicine, vol. 48, no. 12, pp. 1757-1763, 2010.

[90] C. Tyburczy, P. Delmonte, A. R. Fardin-Kia, M. M. Mossoba, J. K. G. Kramer, and J. I. Rader, "Profile of trans fatty acids (FAs) including trans polyunsaturated fas in representative fast food samples," Journal of Agricultural and Food Chemistry, vol. 60, no. 18, pp. 4567-4577, 2012.

[91] M. M. M. Hassanein and A. G. Abedel-Razek, "Chromatographic quantitation of some bioactive minor components in oils of wheat germ and grape seeds produced as by-products," Journal of Oleo Science, vol. 58, no. 5, pp. 227-233, 2009.

[92] A. Stołyhwo, I. Kołodziejska, and Z. E. Sikorski, "Long chain polyunsaturated fatty acids in smoked Atlantic mackerel and Baltic sprats," Food Chemistry, vol. 94, no. 4, pp. 589-595, 2006.

[93] E. S. Lima and D. S. P. Abdalla, "High-performance liquid chromatography of fatty acids in biological samples," Analytica Chimica Acta, vol. 465, no. 1-2, pp. 81-91, 2002.

[94] M. S. Rao, K. Hidajat, and C. B. Ching, "Reversed-phase HPLC: the separation method for the characterization and purification of long chain polyunsaturated fatty acids-a review," Journal of Chromatographic Science, vol. 33, no. 1, pp. 9-21, 1995.

[95] A. Mehta, A. M. Oeser, and M. G. Carlson, "Rapid quantitation of free fatty acids in human plasma by high-performance liquid chromatography," Journal of Chromatography B: Biomedical Applications, vol. 719, no. 1-2, pp. 9-23, 1998.

[96] T. Rezanka and J. Votruba, "Chromatography of very long-chain fatty acids from animal and plant kingdoms," Analytica Chimica Acta, vol. 465, no. 1-2, pp. 273-297, 2002.

[97] W. Kolanowski, D. Jaworska, and J. Weissbrodt, "Importance of instrumental and sensory analysis in the assessment of oxidative deterioration of omega-3 long-chain polyunsaturated fatty acidrich foods," Journal of the Science of Food and Agriculture, vol. 87, no. 2, pp. 181-191, 2007.

[98] G. A. Haward and A. J. P. Martin, "The separation of the C12C18 fatty acids by reversed-phase partition chromatography," Journal of Biochemistry, vol. 46, pp. 532-538, 1950.

[99] J. M. Rosenfeld, "Application of analytical derivatizations to the quantitative and qualitative determination of fatty acids," Analytica Chimica Acta, vol. 465, no. 1-2, pp. 93-100, 2002.

[100] M. I. Aveldano, M. VanRollins, and L. A. Horrocks, "Separation and quantitation of free fatty acids and fatty acid methyl esters by reverse phase high pressure liquid chromatography," Journal of Lipid Research, vol. 24, no. 1, pp. 83-93, 1983.

[101] F.-H. Wang, X.-J. Xiong, X.-F. Guo, H. Wang, and H.-S. Zhang, "Determination of fatty acids in bio-samples based on the precolumn fluorescence derivatization with 1,3,5,7-tetramethyl8-butyrethylenediamine-difluoroboradiaza-s-indacene by high performance liquid chromatography," Journal of Chromatography A, vol. 1291, pp. 84-91, 2013.

[102] T. Řezanka and K. Sigler, "Identification of very long chain fatty acids from sugar cane wax by atmospheric pressure chemical ionization liquid chromatography-mass spectroscopy," Phytochemistry, vol. 67, no. 9, pp. 916-923, 2006.

[103] J. Sajiki and J. Yonekubo, "Determination of free polyunsaturated fatty acids and their oxidative metabolites by highperformance liquid chromatography (HPLC) and mass spectrometry (MS)," Analytica Chimica Acta, vol. 465, no. 1-2, pp. 417-426, 2002. 
[104] T. Řezanka, L. Nedbalová, and K. Sigler, "Identification of very-long-chain polyunsaturated fatty acids from Amphidinium carterae by atmospheric pressure chemical ionization liquid chromatography-mass spectroscopy," Phytochemistry, vol. 69, no. 12, pp. 2391-2399, 2008.

[105] T. Řezanka, O. Schreiberová, T. Krulikovská, J. Masák, and K. Sigler, "RP-HPLC/MS-APCI analysis of odd-chain TAGs from Rhodococcus erythropolis including some regioisomers," Chemistry and Physics of Lipids, vol. 163, no. 4-5, pp. 373-380, 2010.

[106] T. Řezanka, "Identification of very long chain fatty acids by atmospheric pressure chemical ionization liquid chromatography-mass spectroscopy from green alga Chlorella kessleri," Journal of Separation Science, vol. 25, no. 18, pp. 1332-1336, 2002.

[107] T. Řezanka and K. Sigler, "Identification of very long chain unsaturated fatty acids from Ximenia oil by atmospheric pressure chemical ionization liquid chromatography-mass spectroscopy," Phytochemistry, vol. 68, no. 6, pp. 925-934, 2007.

[108] T. Rezanka, "Analysis of very long chain polyunsaturated fatty acids using high-performance liquid chromatographyatmospheric pressure chemical ionization mass spectrometry," Biochemical Systematics and Ecology, vol. 28, no. 9, pp. 847-856, 2000.

[109] T. Řezanka and K. Sigler, "Odd-numbered very-long-chain fatty acids from the microbial, animal and plant kingdoms," Progress in Lipid Research, vol. 48, no. 3-4, pp. 206-238, 2009.

[110] M. Fer, S. Goulitquer, Y. Dréano, F. Berthou, L. Corcos, and Y. Amet, "Determination of polyunsatured fatty acid monoepoxides by high performance liquid chromatography-mass spectrometry," Journal of Chromatography A, vol. 1115, no. 1-2, pp. $1-7,2006$

[111] M. Lísa, M. Holčapek, T. Řezanka, and N. Kabátová, “Highperformance liquid chromatography-atmospheric pressure chemical ionization mass spectrometry and gas chromatography-flame ionization detection characterization of $\Delta 5$ polyenoic fatty acids in triacylglycerols from conifer seed oils," Journal of Chromatography A, vol. 1146, no. 1, pp. 67-77, 2007.

[112] J. I. Teng and N. M. M. Gowda, "Analysis of n-3 fatty acids in fish oils by high-performance liquid chromatography," Chromatographia, vol. 35, no. 9-12, pp. 627-630, 1993.

[113] R. W. Browne and D. Armstrong, "HPLC analysis of lipidderived polyunsaturated fatty acid peroxidation products in oxidatively modified human plasma," Clinical Chemistry, vol. 46, no. 6, pp. 829-836, 2000.

[114] J.-T. Lin, T. A. McKeon, and A. E. Stafford, "Gradient reversedphase high-performance liquid chromatography of saturated, unsaturated and oxygenated free fatty acids and their methyl esters," Journal of Chromatography A, vol. 699, no. 1-2, pp. 8591, 1995.

[115] M. Yamaguchi, R. Matsunaga, K. Fukuda, M. Nakamura, and Y. Ohkura, "Highly sensitive determination of free polyunsaturated, long-chain fatty acids in human serum by highperformance liquid chromatography with fluorescence detection," Analytical Biochemistry, vol. 155, no. 2, pp. 256-261, 1986.

[116] K. Nishimura, T. Suzuki, S. Momchilova, K. Miyashita, E. Katsura, and Y. Itabashi, "Analysis of conjugated linoleic acids as 9-anthrylmethyl esters by reversed-phase high-performance liquid chromatography with fluorescence detection," Journal of Chromatographic Science, vol. 43, no. 9, pp. 494-499, 2005.

[117] N. Noda, K. Umebayashi, T. Nakatani, K. Miyahara, and K. Ishiyama, "Isolation and characterization of some hydroxy fatty and phosphoric acid esters of 10-hydroxy-2-decenoic acid from the royal jelly of honeybees (Apis mellifera)," Lipids, vol. 40, no. 8, pp. 833-838, 2005.

[118] B. Nikolova-Damyanova and S. Momchilova, "Silver ion HPLC for the analysis of positionally isomeric fatty acids," Journal of Liquid Chromatography \& Related Technologies, vol. 25, no. 1315, pp. 1947-1965, 2002.

[119] N. M. Aini, M. M. Yusoff, and H. A. Azhari, "Chromatographic methods to analyze geometrical and positional isomers of fatty acids. A review," in Proceedings of the National Conference on Postgraduate Research (NCON-PGR '09), M. M. Noor, M. M. Rahman, and K. Kadirgama, Eds., UMP Conference Hall, pp. 165-175, Pahang, Malaysia, 2009.

[120] S. Momchilova, B. Nikolova-Damyanova, and W. W. Christie, "Silver ion high-performance liquid chromatography of isomeric cis- and trans-octadecenoic acids. Effect of the ester moiety and mobile phase composition," Journal of Chromatography A, vol. 793, no. 2, pp. 275-282, 1998.

[121] J. L. Guil-Guerrero, P. Campra-Madrid, and R. Navarro-Juárez, "Isolation of some PUFA from edible oils by argentated silica gel chromatography," Grasas y Aceites, vol. 54, no. 2, pp. 116-121, 2003.

[122] C. Sun, Y. Y. Zhao, and J. M. Curtis, "The direct determination of double bond positions in lipid mixtures by liquid chromatography/in-line ozonolysis/mass spectrometry," Analytica Chimica Acta, vol. 762, pp. 68-75, 2013.

[123] S. Casal and B. Oliveira, "Fatty acids: GC analysis," in Encyclopedia of Chromatography, J. Cazes, Ed., pp. 833-845, Taylor \& Francis, New York, NY, USA, 3rd edition, 2010.

[124] T. Seppänen-Laakso, I. Laakso, and R. Hiltunen, "Analysis of fatty acids by gas chromatography, and its relevance to research on health and nutrition," Analytica Chimica Acta, vol. 465, no. 1-2, pp. 39-62, 2002.

[125] R. G. Ackman, "The gas chromatograph in practical analyses of common and uncommon fatty acids for the 21st century," Analytica Chimica Acta, vol. 465, no. 1-2, pp. 175-192, 2002.

[126] M. W. Muriuki, G. G. Dumancas, N. Purdie, and L. Reilly, "Quantification of total $\omega-6$ and $\omega-3$ fatty acids and $\omega-6 / \omega-3$ ratio in human serum using GC-MS," LC-GC North America, vol. 29, no. 1, pp. 60-65, 2011.

[127] H. Kawashima and M. Ohnishi, "Identification of minor fatty acids and various nonmethylene-interrupted diene isomers in mantle, muscle, and viscera of the marine bivalve Megangulus zyonoensis," Lipids, vol. 39, no. 3, pp. 265-271, 2004.

[128] N. Tsevegsuren, K. Fujimoto, W. W. Christie, and Y. Endo, "Occurrence of a novel cis,cis,cis-octadeca-3,9,12-trienoic (Z,Z, Z-octadeca-3,9,12-trienoic) acid in Chrysanthemum (Tanacetum) zawadskii Herb. (Compositae) seed oil," Lipids, vol. 38, no. 5, pp. 573-578, 2003.

[129] A. L. Michaud, M. P. Yurawecz, P. Delmonte, B. A. Corl, D. E. Bauman, and J. T. Brenna, "Identification and characterization of conjugated fatty acid methyl esters of mixed double bond geometry by acetonitrile chemical ionization tandem mass spectrometry," Analytical Chemistry, vol. 75, no. 18, pp. 49254930, 2003.

[130] J. Ecker, M. Scherer, G. Schmitz, and G. Liebisch, "A rapid GC-MS method for quantification of positional and geometric isomers of fatty acid methyl esters," Journal of Chromatography B: Analytical Technologies in the Biomedical and Life Sciences, vol. 897, pp. 98-104, 2012.

[131] F. Destaillats, P.-A. Golay, F. Joffre et al., "Comparison of available analytical methods to measure trans-octadecenoic 
acid isomeric profile and content by gas-liquid chromatography in milk fat," Journal of Chromatography A, vol. 1145, no. 1-2, pp. 222-228, 2007.

[132] A. Liu, R. Terry, Y. Lin, K. Nelson, and P. S. Bernstein, "Comprehensive and sensitive quantification of long-chain and very long-chain polyunsaturated fatty acids in small samples of human and mouse retina," Journal of Chromatography A, vol. 1307, pp. 191-200, 2013.

[133] M. Schreiner, "Quantification of long chain polyunsaturated fatty acids by gas chromatography: evaluation of factors affecting accuracy," Journal of Chromatography A, vol. 1095, no. 1-2, pp. 126-130, 2005.

[134] V. Bláha, D. Solichová, D. Černohorský, M. Brátová, P. Vyroubal, and Z. Zadák, "Bioanalysis of PUFA metabolism and lipid peroxidation in coronary atherosclerosis," Journal of Pharmaceutical and Biomedical Analysis, vol. 22, no. 3, pp. 563-572, 2000.

[135] E. Tvrzická, M. Vecka, B. Staňková, and A. Žák, "Analysis of fatty acids in plasma lipoproteins by gas chromatography-flame ionization detection: quantitative aspects," Analytica Chimica Acta, vol. 465, no. 1-2, pp. 337-350, 2002.

[136] Z. Xu, K. Harvey, T. Pavlina, G. Dutot, G. Zaloga, and R. Siddiqui, "An improved method for determining medium- and long-chain FAMEs using gas chromatography," Lipids, vol. 45, no. 2, pp. 199-208, 2010.

[137] J. K. G. Kramer, C. B. Blackadar, and J. Zhou, "Evaluation of two GC columns (60-m SUPELCOWAX 10 and 100-m CP Sil 88) for analysis of milkfat with emphasis on CLA, 18:1, 18:2 and 18:3 isomers, and short- and long-chain FA," Lipids, vol. 37, no. 8, pp. 823-835, 2002.

[138] P. Delmonte and J. I. Rader, "Evaluation of gas chromatographic methods for the determination of trans fat," Analytical and Bioanalytical Chemistry, vol. 389, no. 1, pp. 77-85, 2007.

[139] A. Timmins, E. J. MacPherson, and R. G. Ackman, "Direct use of methyl tricosanoate as an internal standard and overcoming a potential error in the quantitation of the omega-3 long-chain polyunsaturated fatty acids of marine oils as ethyl esters," Food Chemistry, vol. 70, no. 3, pp. 425-426, 2000.

[140] P. A. Golay, F. Giuffrida, F. Dionisi, and F. Destaillats, "Streamlined methods for the resolution and quantification of fatty acids including trans fatty acid isomers in food products by gas chromatography," Journal of AOAC International, vol. 92, no. 5, pp. 1301-1309, 2009.

[141] C. Ragonese, P. Q. Tranchida, D. Sciarrone, and L. Mondello, "Conventional and fast gas chromatography analysis of biodiesel blends using an ionic liquid stationary phase," Journal of Chromatography A, vol. 1216, no. 51, pp. 8992-8997, 2009.

[142] P. Delmonte, Q. Hu, A.-R. F. Kia, and J. I. Rader, "Preparation, chromatographic separation and relative retention times of cis/trans heptadecaenoic (17:1) fatty acids," Journal of Chromatography A, vol. 1214, no. 1-2, pp. 30-36, 2008.

[143] Q. Gu, F. David, F. Lynen et al., "Evaluation of ionic liquid stationary phases for one dimensional gas chromatographymass spectrometry and comprehensive two dimensional gas chromatographic analyses of fatty acids in marine biota," Journal of Chromatography A, vol. 1218, no. 20, pp. 3056-3063, 2011.

[144] P. Manzano, E. Arnáiz, J. C. Diego et al., "Comprehensive twodimensional gas chromatography with capillary flow modulation to separate FAME isomers," Journal of Chromatography A, vol. 1218, no. 30, pp. 4952-4959, 2011.
[145] W. Meier-Augenstein, "Stable isotope analysis of fatty acids by gas chromatography-isotope ratio mass spectrometry," Analytica Chimica Acta, vol. 465, no. 1-2, pp. 63-79, 2002.

[146] H. Azzian, J. K. G. Kramer, A. R. Kamalian et al., "Quantification of trans fatty acids in food products by GC, ATR-FTIR and FTNIR methods," Lipid Technology, vol. 16, pp. 229-231, 2004.

[147] L. T. Taylor, "Supercritical fluid chromatography for the 21st century," The Journal of Supercritical Fluids, vol. 47, no. 3, pp. 566-573, 2009.

[148] F. J. Señoráns and E. Ibañez, "Analysis of fatty acids in foods by supercritical fluid chromatography," Analytica Chimica Acta, vol. 465, no. 1-2, pp. 131-144, 2002.

[149] J. L. Bernal, M. T. Martin, and L. Toribio, "Supercritical fluid chromatography in food analysis," Journal of Chromatography A, vol. 1313, pp. 24-36, 2013.

[150] G. Pettinello, A. Bertucco, P. Pallado, and A. Stassi, "Production of EPA enriched mixtures by supercritical fluid chromatography: from the laboratory scale to the pilot plant," Journal of Supercritical Fluids, vol. 19, no. 1, pp. 51-60, 2000.

[151] T. Bamba, N. Shimonishi, A. Matsubara et al., "High throughput and exhaustive analysis of diverse lipids by using supercritical fluid chromatography-mass spectrometry for metabolomics," Journal of Bioscience and Bioengineering, vol. 105, no. 5, pp. 460469, 2008. 

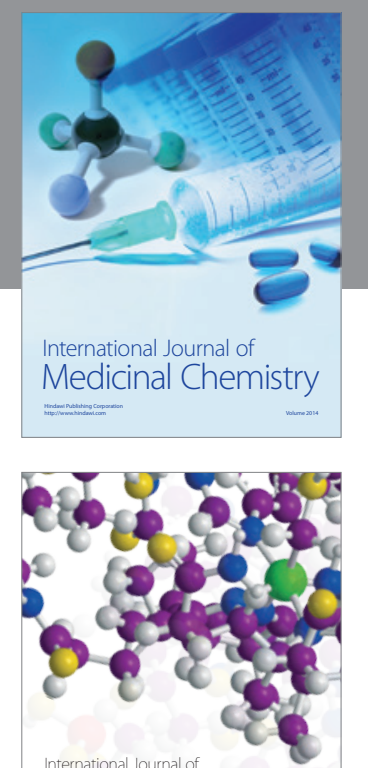

\section{Carbohydrate} Chemistry

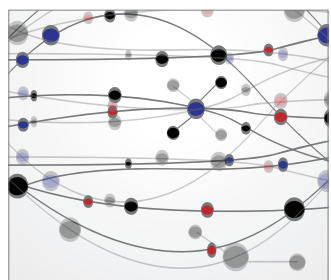

The Scientific World Journal
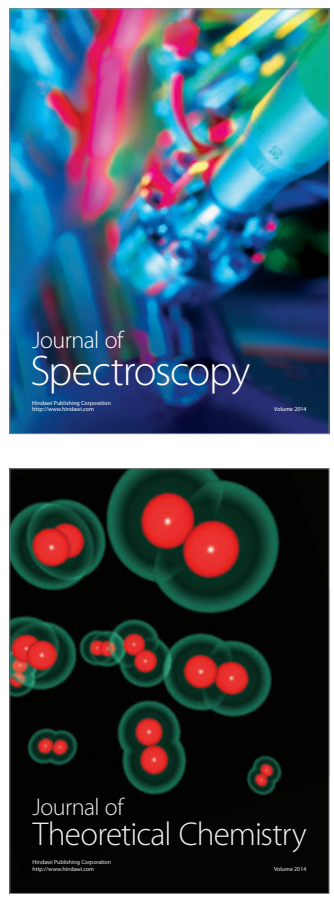
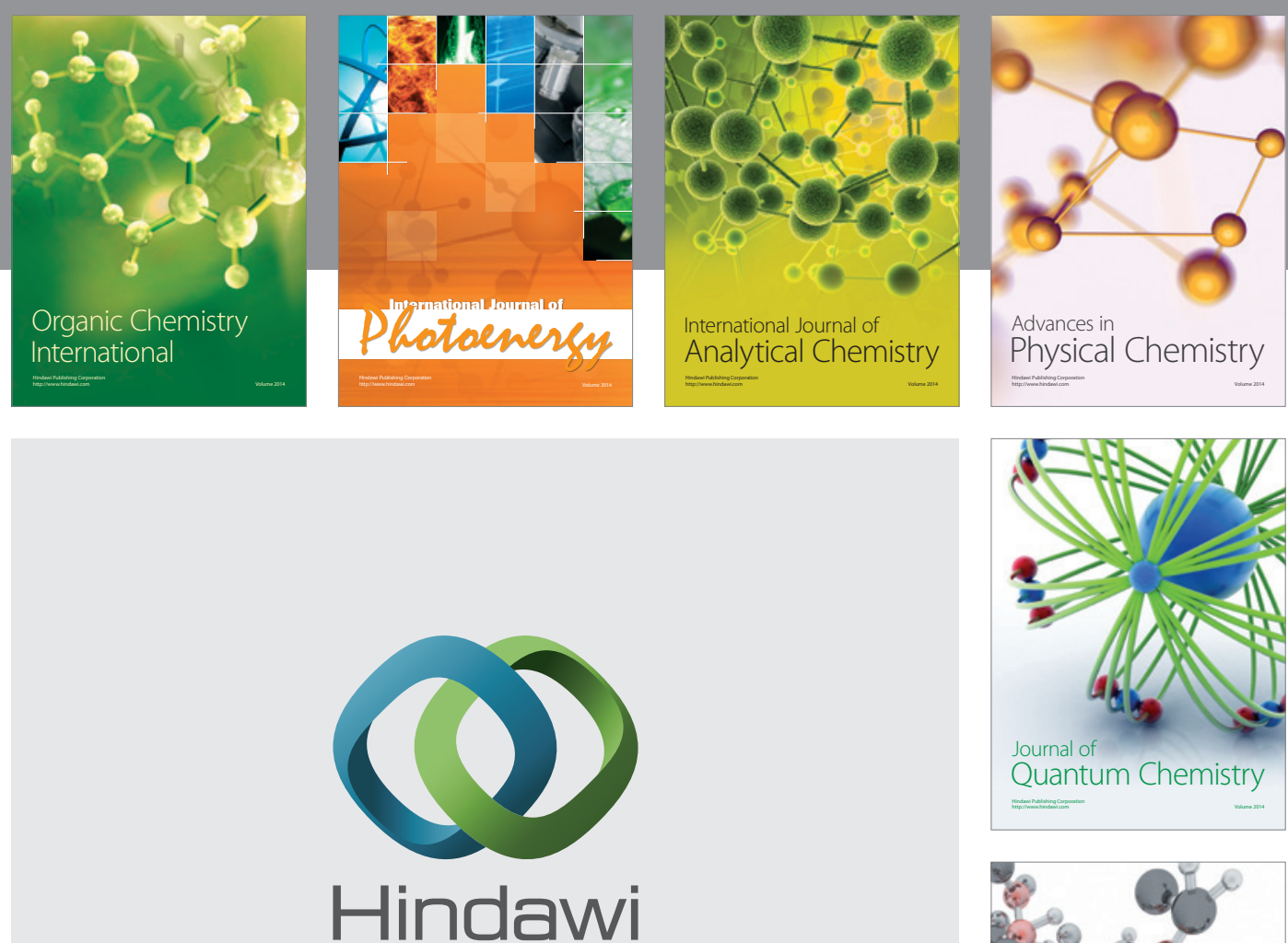

Submit your manuscripts at

http://www.hindawi.com

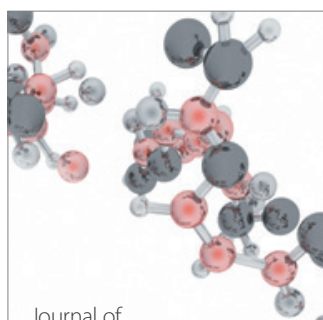

Analytical Methods

in Chemistry

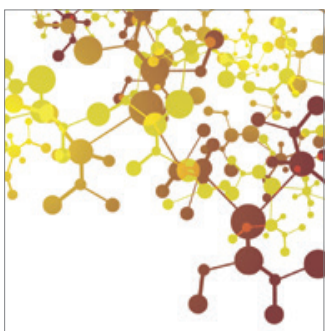

Journal of

Applied Chemistry

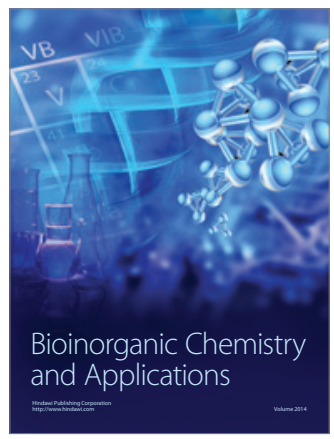

Inorganic Chemistry
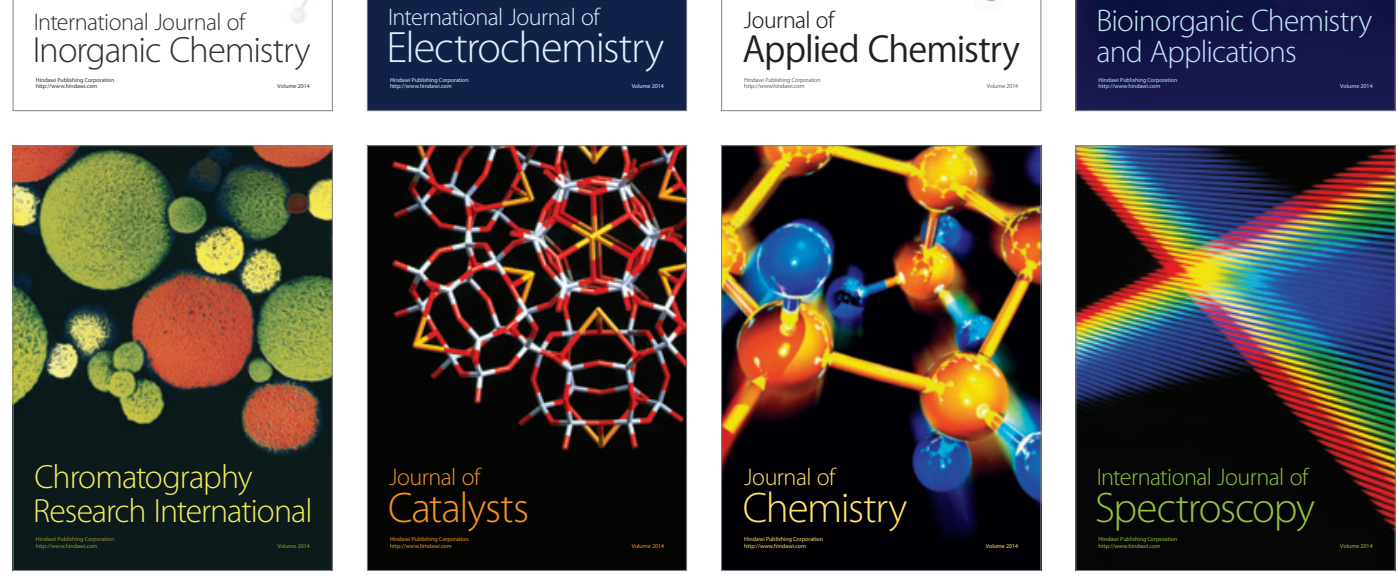